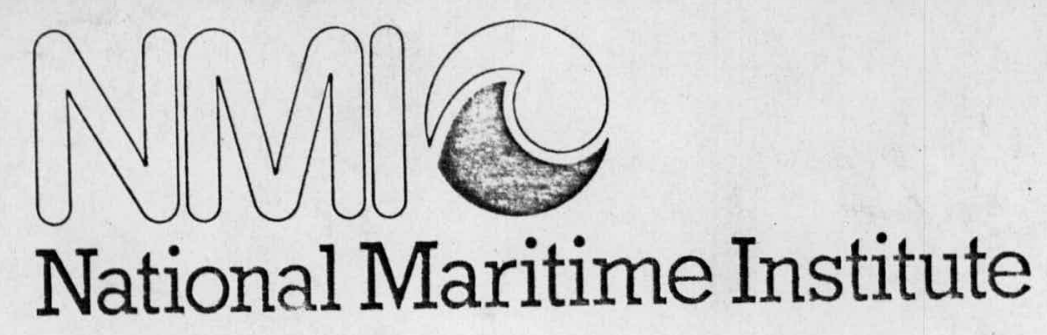

\title{
ESTIMATION OF FLUID LOADING ON OFFSHORE STRUCTURES
}

\author{
by \\ A.E.R.E. LIERARY \\ This rapcrt is ciue buck \\ N Hogben, B L Miller, J W Searle on the atast da:e betiow. \\ and G Ward ${ }^{\times}$
}

Joint NMI/BSRA paper to be presented to the Institution of Civil Engineers

Commissioned by the Department of Energy, Offshore Energy Technology Board

$$
\text { OT }-\mathrm{R}-7614
$$

15 AUG 577

\section{NMI R11}

April 1977

\section{+National Maritime Institute, Feltham, Middlesex}

${ }^{\times}$British Ship Research Association, Wallsend upon Tyne, Tyne \& Wear

National Maritime Institute

Faggs Road Feltham

Middlesex TW14 OLQ

Tel:01-977 0933 Telex:263118 
(C) Crown Copyright 1977

Extracts from this report may be reproduced provided the source is acknowledged 
ESTIMATION OF' FLUID I.(MADING ON

OFFSHORE STRUCTURES

\author{
by \\ N Hogken ${ }^{+}$, B L Niller ${ }^{+}$, J W Searle \\ arid G Ward* \\ Comnissioried by the Department of Energy, \\ Offshore Energy Technology Board
}

OT-R-7614

OPEN DISTRIBUTION

This report may be shown, given or sold to anyone but Crown Copyright is retaired. Reproduction of Crown Copyright material is permitted provided that the source is acknowledged. Further copies may be obtained from National Naritime Institute, Feltham, Middlesex, TW14 OIQ.

\footnotetext{
+National Naritime Institute, Feltham, Middlesex

${ }^{*}$ British Ship Research Association, Wallsend upon Tyne, Tyne \& Wear
}

March $197 \%$ 
This paper is a working guide to methods and associated data for estimating loading on ffshore structures due to waves and currents. Its prinary concern is with existing practice in which the rormula known as Morison's equation is extensively used but some attention is given to diffraction theory methods now quite widely adopted for large monolithic types of structure and a section on the influence of marine roughness on loading is included.

Regarding Morison's equation, a comprehensive review of published data on the relevant coefficients is presented, stressing the considerable uncertainties which still exist in some areas but offering advice on the best values to be used in the light of current knowledge, systematically documented by references to the corresponding data sources. Other important questions discussed include selection of appropriate wave theories and associated particle kinematics, the effects on fluid loading of proximity and inclination of structural members and the special problems of estimating impact or 'slamming' forces.

The section on diffraction theory analysis discusses the interpretation of the results for both fixed and moving bodies and problems of practical application. It also reviews published information on both analytical and numerical solutions including comments on reliability and experimental $v_{a}$ lidation and tabular summaries of the capabilities of an extensive range of methods and computer programs already available.

In discussing marine roughness recent published data indicating the substantial effects which it can have on drag coefficients in both waves and currents are reviewed and advice is given on how these should be estimated.

A general corclusion of the paper is that although data on fluid loading availablc in the literature is very plentiful there are still many serious uncertaintites and gaps in knowledge. It is therefore important that research should continue with emphasis on the need for more reliable data from large ecale structures in the real environment. 
TABLE OF CONTENTS

\author{
1 INTRODUCTION \\ 2 REVIEW OF MORISON'S EQUATION AND DATA ON \\ WAVE FORCE COEFFICIENTS \\ 3 USE OF DIFFRACTION ANALYSIS \\ 4 INFLUENCE OF MARINE ROUGHNESS ON LOADING \\ 5 CONCLUDING REMARKS
}




\section{INTRODUCTION}

This paper is intended as a critical working guide to methods and associated data for estimating fluid loading on offshore structures. Its main concern is with existing practice in which the formula known as Morison's equation (reference 1.1; see also section 2) is most extensively used, but some attention is given to diffraction theory methods now quite widely adopted for large monolithic types of structure. A section is also included which discusses the relevance of some recent research at NMI on the influence of marine roughness on fluid loading.

Morison's equation is a formula for estimating fluid forces which assumes that they can ke divided into two independent components, one in phase with velocity known as the drag force and the other in phase with acceleration known as the inertia force. The formula estimates the magnitude of these force components by invoking two parameters known respectively as the drag coefficient $\left(C_{D}\right)$ and the inertia coefficient $\left(C_{M}\right)$ the values of which must be chosen mainly or the basis of empirical data. The use of the formula is extensively documented in the literature and there is no shortage of published data for determining the coefficients. Unfortunately, in spite of this wide experierce, there are still very serious conflicts and uncertainties regarding the reliability of the method and associated data.

The situation is reviewed in detail in reference 1.2 which discusses the validity of various methods of estimation in terms of three key parameters; these are the Reynolds number $\left(R_{e}\right)$ serving as a criterion of scale effect on drag; the Keulegan-Carpenter number $\left(N_{K}\right)$ which is a measure of the relative importance of drag and inertia forces (1.3); and the ratio 
of structure diameter, (or equivalent dimension) to wavelength, which defines limits beyond which Morison's equation should be superseded by methods based on diffraction theory. A salient conclusion of this discussion is that the scale effects on drag, which are very large, coupled with the shortage of reliable full-scale drag data in waves are a major source of uncertainty in the use of Morison's equation.

In the case of large structures designed for operation in the deep and exceptionally rough waters of the North Sea, the cost of uncertainty in estimation of the sea conditions and resulting loads can be very high and the reference 1.2 makes a number of recommendations for research aimed at improving reliability. In this reference 1.2 it is argued that, in the long term, more basic research is needed with emphasis on large scale experiments, but in the short term it is recommended that "a critical evaluation of existing data, on wave force coefficients should be undertaken so that designers can be given the best advice possible on the basis of present knowledge". Long term basic research including large scale experiments is now in hand at NMI and is referred to later in the paper. The short term recommendation has been fulfilled by completion of an investigation with the title "A Critical Evaluation of the Data on Wave Force Coefficients", 1.4 , carried out by the British Ship Research Association in consultation with NMI, the findings of which are summarised in the next section of this paper.

A crucial feature of the BSRA investigation 1.4 is that it reviews a very wide range of published data on wave force coefficients, systematically documented with tabulated values of the key parameters mentioned above, and discusses reliability and application to practical structures. From this material a sumnary is distilled which indicates in a tabular format suggested values of wave force coefficient in relation to 
the corresponding values of Keulegan-Carpenter number and Reynolds number. It must of course be emphasised that comments on reliability must necessarily be subjective but, in the BSRh review (1.4), care is taken to explain the criteria of assessment and to cite the source material so that readers can form their own opinions.

In presenting this summary it is noted that for some classes of structure involving components with section dimensions which are large relative to wavelength, such as gravity platforms, it may be necessary to use methods based on diffraction theory for estimating wave loads. A section reviewing the availability of such methods and discussing practicel aspects of their use is therefore included in this paper. This begins with a very brief explanation of the physical basis of the methods and their relation to Morison's equation citing references to fuller accounts in the literature. The emphasis however is on working guidance, assessment of reliability and interpretation of results.

A computer program for calculating wave loads by diffraction theory, developed and experimentally validated at NMI, has been available through a number of commercial computer bureaux for some time and has been extensively used by the offshore industry as reported in references (1.5) to (1.8). The authors have thus been able to draw on a wide range cf practical experience in compiling this section of the paper.

Regarding validation of the method, the work at NMI showed good agreement between theory and the results of model tests (1.7) and a number of references are cited reporting similar findings by other investigators. In particular, good agreement was found in experiments at the Hydraulics Research Station (3.29) in random multidirectional waves.

Experience of using the computer program for design studies has shown. the importance of understanding the relation of the results derived by Liffraction theory to the predictions of inertia force given by Morison's cution, in order to ensure the most efficient use of the procram and it: 
output. The practical implications of this point and the possibilities thus offered for substantial saving in computer costs are discussed in the paper. These include combined use of diffraction theory and Morison's equation for analysing some types of structure and ways of interpreting the results to obtain the maximum of useful information from the minimum number of computer runs. It will be noted for example that basic data on inertia coefficients for a wide range of shapes typifying actual structural components can be accumulated as a by-product of diffraction theory computations and reference will be made to sources of data obtained in this way. Brief reference will also be made to recent work at NMI (1.8 and 1.9) using a modified version of the diffraction theory program to investigate the dynamics of moored platforms in waves.

As noted earlier, there is also some basic research in progress at NMI on the use of Morison's equation which has included some work on the influence of marine roughness. A detailed account of some of this has been published in a separate paper (1.10) but a short section is included here discussing the practical implications of the more significant results so far available. Extensive tests with smooth and rough cylinders both in steady flow in wind tunnels and more recently in waves in one of the NMI ship tarks have provided strong evidence that roughness of a degree to be expected on actual North Sea structures can cause large increases in drag coefficient at high Reynolds number.

A number of other relevant investigations, sponsored by the Department of Energy, are being conducted at NMI and other laboratories for which, at the time of writing, results have not yet been published A review of progress in the overall programme of research may be found in reference 1.11. This includes an account of a major large scale experiment in the sea at Christchurch Bay which should make an important contribution to improvement in the reliability of wave loading estimates. A selective review of other itens of 
the programme may be found in reference 1.12. The paper concludes with the suggection that in future more emphasis should be placed on collection of full-scale data from structures s.t sea.

\section{REVIEW OF MORISON'S EQUATION AND WAVE FORCE COEFFICIENTS}

As stated in the Introduction, the equation generally used for estimating the wave loads on offshore structures is based upon the work of Morison et al (2.14),

$$
F=\frac{1}{2} \rho C_{D} A U|U|+\rho V C_{M} \frac{d U}{d t}
$$

In this equation it is assumed that the fluid forces on a fixed body in an unsteady flow are given by the linear superposition of a drag force, dependent upon the square of the velocity $\left(U^{2}\right)$ and acting on the projected frontal area, $A$, and an inertia force, dependent upon the acceleration $\left(\frac{d U}{d t}\right)$ and the volumetric displacement, V. Several studies have shown that the mathematical form of this equation is satisfactory but a particular difficulty in using it in the design of offshore structures has been the choice, from a wide range of published values, of the empirical coefficients $C_{M}$ and $C_{D}$ appropriate to both the structure and its design sea-states. It is the aim of this section to provide advice on this choice, based upon an appraisal of current literature (references 2.1 to 2.26 and summarised in table 2.1), with an indication of the reliability which may be attributed to the values suggested.

It is emphasised, however, that there is wide scatter in published values of $C_{M}$ and $C_{D}$ and consequently the 'average' values suggested (figure 2.1) are seen as the best estimates available in a situation of cons iderable uncertainty.

Most of the literature on wave force coefficients (table 2.1) has been concerned with the horizontal wave forces on circular cylinders that are vertical 
and pierce the free surface. In this particular case equation 2.1 takes the original form suggested by Morison:

$$
F^{\prime}=\frac{1}{2} \rho C_{D} D U|U|+\rho \pi \frac{D^{2}}{4} C_{M} \frac{d U}{d t}
$$

where $F^{\prime}$ is the force per unit length on a cylinder of diameter $D$ and $\mathrm{U}$ is the horizontal component of the water particle velocity. In this section the main concern is with the cases where the inertia forces and the drag forces are of comparable magnitude. This is the regime in which the Morison equation is generally assumed to be applicable and it is defined as that regime for which the diameter of the cylinder is less than about $20 \%$ of the wavelength $(D / \lambda \leqslant 0.2)$. It corresponds to the physical assumption that the values of velocity and acceleration are sensibly constant over distances equal to the member diameter, which is generally the case, for example, for members of steel jacket structures. For forces on large structures, where $D / \lambda>0.2$, a diffraction theory should be used (see section 3 ).

\subsection{Drag Forces}

In steady flow, the drag coefficient, $C_{D}$, has been found to be well correlated with the flow Reynolds number, $\mathrm{R}_{e}$, as documented, for example, in references 2.27 to 2.29. For the circular cylinder in steady flow there are several flow regimes characterised largely by the behaviour of the flow in the wake and by the positions of boundary layer separation. In steady flow over smooth cylinders, these regimes may be distinguished by the flow Reynolds numbers as shown in figure 2.2 and as listed below.

$$
\begin{array}{ll}
\mathrm{R}_{\mathrm{e}} \leqslant 2 \times 10^{5} & ; \quad \begin{array}{l}
\text { Subcritical regime, laminar separation, } \\
\text { wide wake, } \mathrm{C}_{\mathrm{D}}=1.2 .
\end{array} \\
2 \times 10^{5} \leqslant \mathrm{R}_{\mathrm{e}} \leqslant 5 \times 10^{5} ; \quad & \text { Critical regime, change from laminar to } \\
& \text { turbulent separation as } \mathrm{R}_{\mathrm{e}} \text { increases } \\
& \text { accompanied by rapid narrowing of wake and } \\
& \text { decrease in } C_{D} \text { to a minimu? value. }
\end{array}
$$




$$
\begin{aligned}
5 \times 10^{5} \leqslant R_{e} \leqslant 5 \times 10^{6}, ; & \begin{array}{l}
\text { Supercritical regime, turbulent } \\
\text { separation, wake widening and } C_{D} \text { increasing } \\
\text { with increasing } R_{e}
\end{array} \\
R_{e} 25 \times 10^{6} & ; \quad \text { Postcritical regime, turbulent } \\
& \text { separation, constant } C_{D} \simeq 0.6-0.7 \\
& \text { (Roshko terms this Transcritical }(2.29))
\end{aligned}
$$

The published values of drag coefficients in waves show an overall trend with Reynolds number which is broadly similar to that found in steady $\mathrm{f}^{\prime}$. ow where $C_{D}$ decreases considerably with Reynolds number over the approximate range $10^{4}<\operatorname{Re}<10^{6}$. Although there are, therefore, good grounds for retaining the Reynolds number as a relevant flow variable, great care must be taken if steady flow results are applied to wave flows. In particular the flow close to the cylinder is likely to be strcngly influenced by two specific flow pheromena not present in steady flow,

(i) the water particle motions are orbital, and (ii) the oscillatory nature of the flow causes the 'wake' of the cylinder to be swept back and forth over the cylinder.

The process of transition frcm laminar to turbulent flow, upon which the critical changes in flow characteristics depend, is itself likely to depend on the above features. In steady flow the general effects of free stream turbulence and surface roughness are to reduce the critical Reynolds number below that found for smooth cylinders in smooth external flows. Recent work on rough cylinders in planar oscillatory flow by Sarpkaya (2.20) and in waves at NMI (4.11) have shown that the overall effects are similar in oscillatory flow but have also emphasised the need for caution in applying either steady flow or planar oscillatory flow results to waves.

In figure 2.1 which gives suggested values for $C_{M}$ and $C_{D}$, the Reynolds number ranges are approximate and are based on results for both steady and oscillatory flow conditions. The figure also shows the influence of the Keulegan-Carpenter number, which as shown in appendix I is a measure of the relative imoortance of drae and inertia forces. 


\subsection{Inertia Forces}

Inertia forces in general

are due to the relative acceleration.

between a body and a fluid. The present section is concerned only with members of fixed structures having diameters small enough for wave scattering to be neglected and for the ambient acceleration to be assumed uniform over the diameter. Inertia forces in this case may be related to the acceleration of the ambient fluid by means of the inertia coefficient $C_{M}$ as indicated in equation 2.1. In section 3.1 it is shown that $C_{M}$ may be determined theoretically by application of diffraction analysis methods for waves assumed long in relation to diameter. Reference material for values derived in this and other theoretical ways is cited in section 3. Consideration is given in section 3.4 .2 to the interpretation of inertia and diffraction forces in the more general case of moving structures.

Theoretical analysis as discussed in section 3, however, is strictly only applicable to an ideal, inviscid fluid; viscosity and other real fluid effects encountered in practice in wave motion, such as interaction between drag and inertia forces in oscillatory flow, can lead to uncertainties in the value of $\mathrm{C}_{\mathrm{M}}$ and it need not necessarily be equal to the potential flow value. Generally it is found that when there are interaction effects, $\mathrm{C}_{\mathrm{M}}$ values for cylinders are less than the theoretical potential flow value of 2.0 .

\subsection{Wave Considerations}

Published wave force coefficient values obtained from any one experiment have generally been derived using a particular wave theory in association with a particular data analysis technique and are thus a function of the procedures used. Therefore, in suggesting values for these coefficients from an overall appraisal of many experiments, it is not appropriate to associate them with any one theory. It is suggested that a wave theory appropriate to the wave conditions being considered, such as wave steepnoss $(H / \lambda)$ and water depth to wavelength ratio $(d / \lambda)$, should be used. 
Guidance on the choice of wave theory is discussed briefly later, and more fully by Dear in reference (2.30). It is worth mentioning here that there are two main approaches adopted when designing structures to withstand

wave forces. The first is the 'design wave' approach which designs agairst the possibility of structural failure when experiencing a single large wave. The second, particularly relevant to the persistently harsh wave climate of the North Sea, considers the possibility of fatigue failure due to the accumulated damage of repeated cyclic loadings. The design wave approach is generally drag dominated, at least for relatively small diameter members, whereas in the fatigue approach drag and inertia are approximately comparable and the interaction effects mentioned earlier may consequently be of importance. Methods for estimating the loading spectra, based upon spectral descriptions of the waves have been developed, for example, by Borgman (2.31, 2. 32) and are discussed in detail by Wiegel (2.33).

2.4 Published $\mathrm{C}_{\mathrm{D}}$ and $\mathrm{C}_{\mathrm{M}}$ values Those papers in the literature survey which contained explicit data for the wave force coefficients are summarised in table 2.1. In each case the coefficients were obtained in the original study by particular methods of data analysis and in association with particular wave theories. If these values are considered for direct application to another situation then it should preferably not be significantly different to that of the original experiment. In such cases the reliability will be similar to that which is quoted for the experiments and which is summarised in table 2.1.

The wave force coefficiert values in table 2.1 are qualified with respect to both Reynolds number and Keulegan-Carpenter number. These two parameters were chosen on the basis of dynamic similarity (dimensional analysis) and from a study of the literature; they were considered to be the best available parameters with which to define the wave force cuefficients for specified conditions. Some recent experiments by Sarpkija (2.20) in the contenlled 1 boratory conditions of simple harmonic 
oscillatory flow in a U-tube apparatus, led him to the conclusion that $\mathrm{C}_{\mathrm{M}}$ and $C_{D}$ in these flow conditions are definitely functions of Reynolds number and Keulegan-Carpenter number. There are, however, other effects in the real sea situation, such as orbital motion of the fluid particles and irregularity of the seawaves, which are not taken into account by the above two parameters.

Reynolds number and Keulegan-Carpenter number are based upon a represertative . water particle velocity which must be calculated from a suitable wave theory. The value normally chosen is the amplitude of the orbit velocity normal to the axis of the cylinder, $U_{\mathbb{M}}$, in the case of the Keulegan-Carpenter number and usually also in the case of Reynolds number. The calculated orbital velocity is dependent on the wave theory selected and the velocity varies both with the depth below the surface and with position in the wave. If the variation of the force coefficients with depth below the water surface is not to be considered then it is suggested that the above two parameters should be calculated using the maximum horizontal velocity at the still water level. This is the approach used in table 2.1 unless otherwise stated. In discussing drag forces it has already been noted that, in steady flow, the Reynolds number is well established as a correlation parameter for $C_{D}$ and provides boundaries for fairly well-defined regimes. Published $C_{D}$ data for oscillatory flow shows a general trend with Reynolds number similar to that for steady flow, but the boundaries between the regimes and the associated fluid behaviour are not yet so clearly established. In presenting the $C_{D}$ data for oscillatory flow in fjgure 2.1, it is convenient to refer to three regimes similar to those defined for steady flow; these are 'subcritical', 'critical' and 'postcritical'. The postcritical regime, for the purposes of this study, has been considered to embrace the supercritical and postcritical regimes of the steady flow case. This is 
because the published ${ }_{D}$ values for oscillatory flow at these Reynolds numbers do not show similar behaviour to steady flow; they exhibit a large scatter but there is a trend towerds a constant mean value independent of Reynolds number once the uncertain critical region is passed. It should be emphesised that these regimes are not well defined experimentally. They have been chosen for convenience in discussion and classification of the published wave force coefficients and their reliability, but they are, however, based on available literature.

The Keulegan-Carpenter number represents the relative importance of drag over inertia forces and can be shown to be proportional to their ratio (see appendix I). In the form $N_{K}=\frac{U_{M} T}{D}$ it is strictly only applicable to simple harmonic flow. and in the complex flows of non-linear sea waves its definition is somewhat arbitrary. On the basis that the significant forces are exerted in the surface region (tipping moments are even more strongly weighted towards the surface) the definition of $\mathrm{N}_{\mathrm{K}}$ for wave flows is usually based upon the maximum velocity at the still water level. Using linear wave theory this can be expressed (see appendix $I$ ) as $N_{K}=\frac{\pi H}{D}$ in deep water.

Theory and experiment indicate that the drag force dominates in Morison's equation at high Keulegan-Carpenter number values, and that the inertias force dominates at low values; there are intermediate values a.t which the drag and inertia forces attain similar magnitudes. Thus three KeuleganCarpenter number regimes naturally arise as indicated in figure 2.1. The flow behaviour at the intermediate Keulegan-Carpenter numbers is very complex and uncertain, and as this regime is also that in which transition from drag to inertia dominance takes place, it has been termed the "critical regime" in figure 2.1.

The flow in the portion of the cycle when maximum forces are experienced asimptotically approaches steady, 'viscous' flow as $\mathrm{N}_{\mathrm{K}} \rightarrow \infty$ or inviscid, potential flow as $\mathrm{N}_{K} \rightarrow 0$. In the first case $\left(\mathrm{N}_{K} \rightarrow \infty\right)$ the maximum forces occur 
acceleration. The intermediate kcundaries of the three regimes are not precise and have been chosen for convenience in the discussion and classification of the published wave force coefficients and their reliability. It is, however, stressed. that the values presented in fig. 2.1 are based upon the available information.

clearly, the accuracy of evaluation of wave force coefficients is not independent of the loading regime in which the experiment was conducted. Data predominantly comprising drą̧ forces enables accurate evaluation of ${ }_{D}$ but not $C_{M}$ and vice versa. Dean (2.34) recently presented a detailed analysis. of the influerce of loading regime on the uncertainties in $C_{D}$ and $C_{M}$ which showed that the large scatter in published coefficients could, at least partially, be attributed to lack of discrimination in the selection of suitable data for each particular ccefficient. BSRA (1.4) have also presented calculations, based upon linear wave thecry and a somewhat simpler analysis than Dean's, which emphasise the importance of Keulegan-Carpenter number not only as a measure of the relative importance of drag and inertia (and thus $C_{D}$ and $C_{M}$ ) but also as a parameter which influences the scatter in $C_{D}$ and $C_{M}$. Some results of this approach are presented in appendix II; they demonstrate the above points and also show the influence of the ratio of $C_{D}$ to $C_{M}$.

\subsection{Discussion of Suggested Wave Force Coefficient Values Given in Figure 2.1 \\ The wave force coefficient values discussed below are mainly} concerned with the horizontal wave forces on vertical, circular cylinders which are isolated and pierce the free surface. This is due to a lack of available data for other types of structure and other conditions. In particular, there is very little laboratory scale data for horizontal cylinders in waves and, to the authors' knowledge, no published full scale data at all. Also the effect of roughness in wave conditions has received very little consideration in the literature (see section 4 ). 
- As stated in its, caption, figure 2.1 is a summary of suggested values of $C_{M}$ and $C_{D}$ 'Derived from the Literature' and care his been taken to ensure that all the advice given is supported by data in published sources available at the time of writing. Suggestions based on unpublished work are not included partly because it is considered important that readers should be able to form their own opinions about the values cited and partly because the interpretation of unpublished data may often be revised before publication. The authors are however very conscious that research is a continuing process and that the literature is expanding rapidly. They therefore emphasize very strongly that the contents of figure 2.1 must be regarded as subject to continuing revision in the light of new information.

\subsubsection{Box' 1}

There j.s a considerable body of data for the subcritical

Reynolds number regime, but there is some uncertainty in applying model values, obtained in idealized controlled cunditions, to practical sea conditions. In any case it is unlikely that this order of Reynolds number would be considered in design calculations but the coefficients are included in figure 2.1 for completeness. The wave force coefficient values suggested are those of Keulegan and Carpenter (2.11) shown in figure 2.3. These results were obtained in 1-dimensional. oscillatory flow as were the almost identical results of Sarpkaya (2.19). Susbielles et al (2.23) used the values reproduced in figure 2.3 to calculate local wave forces on a vertical pile and obtained agreement with measured forces to within $10 \%$.

Both in these experiments $(2.11,2.23)$ and, more recently, in wave experiments at NMI (2.39) the agreement between measured forces and values calculated from the Morison equation is generally good except near KeulegranCarpenter numbers of about 10 to 15. This critical behaviour is associated with 
large changes in the, coefficients, as shown in figure 2.3, and with the formation of strong vortices. Consequently the errors and uncertainties in this region of Keulegar-Carpenter numker are large.

\subsection{2 'Boxes' 2 and 3}

In the critical Reynolds number regime, published data exhibit considerable scatter which cannot be resolved from a study of the literature. Several sets of data fall partly in the regime but it is not possible to identify precisely the Keulegan-Carpenter numbers associated with all of these. The scatter in $C_{D}$ values obtained in waves, as shown for example in the data presentations of references 2.5 and 2.25 , is very large and thus there is a great deal of uncertainty in deciding on what values should be used. It is suggested that a reduction in the $C_{D}$ value from 1.2 to 0.6 be assumed as the Reynolds number increases within the regime from about $5 \times 10^{4}$ to $5 \times 10^{5}$.

This proposal is based on the data presentations of references $2.1,2.17$ and 2.20. The $C_{M}$ value of 1.5, suggested in figure 2.1, is based on values given in the references cited, though at Keulegan-Carpenter numbers greater than about 25 the value of $C_{M}$ is of diminishing importance as drag then becomes increasingly dominant. It should be noted that Sarpkaya (2.20) found from his experiments in simple harmonic flow that within this Reynolds number regime $C_{M}$ is, in general, an increasing function of Reynolds number and a decreasing function of Keulegan-Carpenter number; no such functional relationships have been found in waves.

The reliability in total and local wave forces calculated using the values suggested in "boxes" 2 and 3 in figure 2.1 carnot be assessed rigorously and in general errors of the order of $100 \%$ or more are roseible.

In view of the very wide scatter of the force coefficients in this Reyrolds number regime attention should be drawn to the use of a statistical approach in which distributions rather than single fixed values of force 
coefficients are used to estimate loading probabilities. Such an approach has been described in detail in a paper by Bretschneider (2.2) in which its application has been illustrated in a reanalysis of the data of Wiegel et al (2.25). Such a probabilistic approach needs to be considered together with the design philosophy adopted, as discussed in section 2.8 .

\section{5 .3 Box $^{\prime} 4$}

The majority of the data from the Gulf of Mexico $(2.1,2.5,2.8$, 2.24) fall in the postcritical Reynolds number regime at high KeuleganCarpenter numbers and a mean $C_{D}$ value of 0.6 was generally obtained by all analysts of this data. This value was also obtained in the Bass Straits experiment (2.12) in which measurements of wave particle velocity were made and from which it was concluded that, at high Reynolds number, $C_{D}$ is independent of Reynolds number. Rance (2.17) found $C_{D}=0.6$ at high Reynolds number and high Keulegan-Carpenter number in his pulsating water channel experiments. Also, as mentioned earlier, at high Keulegan-Carpenter numbers the fluid motion around the cylinder is 'quasi-steady' and consequently, at postcritical Reynolds numbers, drag coefficients are expected to be close to those of steady flow, which are in the range of about 0.6 to 0.7. A constant value of $C_{D}=0.6$ is therefore suggested for this regime. The $C_{M}$ value suggested is 1.5 which is based on values given in the references, though at high Keulegan-Carpenter number $C_{M}$ is of little significance because drag is then dominant.

It is apparent from the data analyses used in references 2.1, 2.5, 2.8 and 2.24 that the estimation of the total wave forces, integrated over the total depth of a member, is far more reliable than that of the local forces. Examples are given in these references in which local force maxima, calculated using average values of coefficients, differ by more than $50 \%$ from the measured values (the standard deviation is around 50\%). However, 
for the calculated forces integrated along the member, the agreement is much better and often within 10\%. Agreement is also good between measured total forces and calculated total forces at various points within a wave cycle, using constant $C_{M}$ and $C_{D}$ values. No measurements of fluid motion were made in these experiments. The distributions of acceleration and velocity needed for determining $C_{M}$ and $C_{D}$ had. therefore to be calculated by indirect methods from the measured surface elevation histories. This fact may well account for much of the scatter in the data.

Allowing for different procedures and conditions to those used and experienced in the above references, a subjective reliability of $20 \%$ is considered to be conservative for the case of the total (vertically integrated), horizontal force, with much larger errors, of $50 \%$ or more, possible for local forces.

In discussing data for postcritical Reynolds numbers mention must also be made of the recent laboratory experiments by Sarpkaya using simple harmonic oscillatory flow in a U-tube apparatus $(2.20,2.62)$. At Reynolds numbers around $1.5 \times 10^{6}$ and Keulegan-Carpenter numbers greater than 20 , the drag coefficient, $C_{D}$, was found to be between 0.6 and $0.65(2.62)$. In assessing the significance of results from experiments in planar oscillatory flow it is important to appreciate that, despite the agreement with postcritical steady flow and some wave experiments, rectilinear oscillatory motion is not a complete modelling of the orbital motion or of the directional and spectral properties of the flow in sea waves experienced by offshore structures.

\section{5 .4 Box' 5}

For lower values of the Keulegan-Carpenter number, the situation is far less certain than in 'Box' 4, due to a lack of available data and the 
importance of the inertia force in this regime. It is suggested that $C_{D}=0.6$ and $C_{M}=1.5$ be used, but higher values may be encountered. In view of the lack of data, the reliability is considerably less than that for high Keulegan-Carpenter numbers.

\section{5 .5 Box' 6}

For large diameter cylinders, for which the Keulegan-Carpenter number is low and diffraction effects are negligible (diameter/wavelength $\simeq 0.2)$, there are several laboratory model tests $(2.3,2.6,2.9,2.10$, 2.22) from which a value of $C_{M}=2.0$ is suggested for design purposes, with the drag force regarded as negligible. The largest difference between measured and calculated total forces in the literature, using this value, is about $20 \%$ but generally agreement between calculated and measured force for both local and total forces is excellent. The scale effect in applying these results to full size conditions is likely to be less severe than for drag dominated regimes as the effects of Reynolds numbers at these KeuleganCarpenter numbers are expected to be much less marked.

\subsection{Other Factors Influencing Wave Force Coefficient Values}

The wave force coefficient values suggested in figure 2.1 are

limited to the horizontal wave forces on smooth, vertical,

circular cylinders that are isolated and pierce the free surface, though it is suggested that, in the absence of specific data, they should be considered as applicable to horizontal submerged cylinders as well. Other physical factors likely to influence the coefficients cannot be considered in such detail owing to lack of published information. Surface roughness is an exceptional case and is discussed separately in Section 4; otherwise only general guidarice can be given as discussed below. 


\subsubsection{Variation with Phase in the Wave Cycle}

Low Reynolds number results (2.11) suggest that wave fiorce coefficients depart significantly from a mean value over a wave cycle only near Keulegan-Carpenter numbers of 15 . Several results $(2.5,2.11,2.12,2.14$, $2.18,2.19,2.26,2.39)$ suggest that use of constant mean values, in general, will not result in errors any greater than those shown in figure 2.1.

\subsubsection{Variation with Wave Height, Wave Period and Depth Below Surface}

There is a trend for $C_{D}$ to decrease with increasing wave height and period at all depths below the surface (2.5). Pierson and Holmes (2.35) suggest that variation in wave force coefficients with depth below the surface is significant, though results from the Gulf data (2.5) suggest $C_{D}$ is more or less constant with possibly smaller values near the surface; $C_{M}$ appears to increase significantly towards the surface. These variations are not understood well enough to suggest values which alter with depth. It can be pointed out, however, that the wave height, wave period, water depth and depth below the surface influence the choice of coefficients via both the wave theory chosen and the choice of representative velocity for evaluating Reynolds number and Keulegan-Carpenter number.

\subsubsection{The effects of neighbouring cylinders and finite length} The flow over groups of cylinders in which the cylinders are not far apart is quite different from the flow past individual cylinders in isolation. Consequently the forces on a structure are not, in general, equal to the sum of the forces which would be exerted on its constituent members in isolation. In addition, most values of $C_{D}$ and $C_{M}$ quoted are for cylinders which are long in comparison with their diameter but it is well known (2.36) that for short cylinders $C_{D}$ is reduced, at least in steady flows.

Comnon practice in steady flow calculations (2.37) is to allow for whelding (by upstream cylinders) and finite length by using empirical 
Experimental studies of proximity effects (2.27, nu ?.3? ) indicate that drag can also be increased for some flow directions. For example (2.38), the $C_{D}$ values found in towing tests on a six-column array of vertical cylinders varied up to 0.7 at high Reynolds number and between 0.2 and 1.5 at low Reynolds number depending upon cylinder position and flow orientation. In this work the cylinders were in two lines of 3 , the lines being 4.7 diameters apart and the cylinders only 2.2 diameters apart along the line. In tests on $3 \times 3$ arrays with 3 diameter spacings much smaller variations were found both in steady flow (wind tunnel) experiments at NMI (1.11) and in oscillatory flow (pulsating water tunnel) at HRS. Both these studies indicated that the total load on the array varied relatively slightly $(\sim 20 \%)$ with orientation and that the use of shielding factors was inappropriate for individual cylinders unless the flow direction was accurately known. Towing tests on model semisubmersibles at Glasgow University have surreste' ihat, when cylinders are aligned with the flow the use of shielding factors is appropriate (see 2.37 nnd : or typical values).

For cylinders spaced normal to the flow (2.40) there seems to be no effect on $C_{D}$ unless the centre to centre spacing $(S)$ is less than two diameters. Boiler tube experiences, however, suggest that even at these spacings there can be serious dynamic problems which could be relevant to conductor tube arrays.

There seems to be no published data on flow interference in waves. There are, however, several obvious ground rules as far as drag is concerned:

(1) If the cylinders are spaced further apart than half the wave height and the water is reasonably deep with no current, $\mathrm{C}_{\mathrm{D}}$ is probably unaffected since the wake of any cylinder can, at most, be of the order $\mathrm{H} / 2$ in length.

(2) If the Keulegan-Carpenter number is large then steady flow ${ }^{C}$ values may be used. If the cylinder under consideration is 
shielded for both flow directions (fore and aft) and is sufficiently close to those shielding it, steady flow shielding factors mat tentatively be assumed but only for restricted flow directions. In general the application of shiflding factors for wave flows is not justified.

The inertia coefficient, $\mathrm{C}_{\mathrm{M}}$, can be calculated from potential flow theory as demonstrated by Dalton and Helfinstine (2.41) who discuss in detail the evaluation of $C_{M}$ for groups of cylinders.

Broadly, they found that for cylinders in-line with the oncoming flow $C_{M}$ was reduced but only by significant amounts for $S / D<4$. When the cylinders are side by side $\mathrm{C}_{\mathrm{M}}$ is increased but again only by significant amounts for $\mathrm{S} / \mathrm{D}<4$.

The interaction between drag and inertia forces in oscillatory flow for groups of cylinders is unknown.

\subsubsection{Inclined Cylinders}

For inclined cylinders, it is suggested that the cross flow principle should be assumed (i.e. normal pressure force is assumed to be independent of tangential velocity), and Morison's equation, using the component of fluid velocity normal to the axis of the cylinder should be used, as proposed by Chakrabarti (2.4). This was the only information available on inclined cylinders in waves, and no wave force coefficients were suggested due to the wide scatter obtained in the derived values of the coefficients. It is thus suggested that the $C_{M}$ and $C_{D}$ values of figure 2.1, should be used with Reynolds number and Keulegan-Carpenter number evaluated using the cylinder diameter and the maximum normal velocity component. The degree of reliability cannot be assessed.

A review of information available for $C_{D}$ as a function of Reynolds number on smooth and stranded (wire rope) cylinders inclined in a vertical plane parallel to a steady flow has been presented by Glenis $(2.1)$. 


\subsubsection{Wave Force Coefficients for Other Structural Shaves \\ The only structural shape, other than circular cylinders,}

for which wave data are available, is the sphere and then only at low

Reynolds numbers. The values suggested are $C_{D}=0.7$ and $C_{M}=1.2$, based on reference 2.7 where measured and calculated wave forces agreed, in general, to within about $25 \%$. Wave force coefficients for a sphere have also been fiven as a function of Keulegan-Carpenter number from an experimert in idealised 1-dimensional oscillatory flow (2.19). At high Reynolds number, $C_{D}$ values are likely to be smaller. Steady flow results $(2.27)$, give $C_{D}=0.5$ up to Reynolds numbers of $5 \times 10^{6}$, and $C_{D}=0.1$ at very high Reynolds numbers. $C_{D}$ values as a function of Reynolds number have been published for an extensive number of 2 -dimensional prismatic shapes in a steady flow by Delany and Sorenson (2.28) and by Hcerner (2.27). Values of $C_{D}$ tend to remain constant over all Reynolds numbers for shapes with geometric discontinuities but as the discontinuities become smoother the variation of $C_{D}$ values with Reynolds number tend to be more like those for circular cylinders. $C_{M}$ may be calculated by potential flow theory, but any interaction with drag forces in viscous, oscillatory flow cannot be assessed.

It should be noted that the cross flow principle, as discussed in section 2.6.4, is only applicable to 2-dimensional prismatic shapes.

\subsubsection{Wave Force Coefficients for Pipelines}

The effect of the proximity of the seabed on a horizontal cylindrical pipeline is to increase both the horizontal and vertical wave forces, the effect becoming more significant in shallow water $(2.43,2.44)$. Wave force coefficients should be increased above their free stream values to allow for this. Wilson and Reid (2.44) recommended that $C_{M}$ should be increased by a factor of $1-1.7$ and a minimum value of $C_{D}=1.0$ should be used. 
For horizontal pipelines adjacent to the seabed and subject to tidal currents, the design curves for lift and drag given by the Hydraulics Research Station (2.45), are appropriate.

\subsubsection{The Effect of Currents}

The presence of a current seems to influence $C_{D}$ and not $C_{M}(2.12,2.26)$, probably because a current sweeps the vortices away from the structure. For a current approximately parallel to the wave direction, it is suggested that the current velocity. should be added vectorially to the wave particle velocity both for the definition of Reynolds number and for use in Morison's equation. The evaluation and meaning of Keulegan-Carpenter number when such a current is present is uncertain, though, recalling that the Keulegan-Carpenter number is essentially a measure of the relative magnitude of drag to inertia, it is suggested that in most situations the vectorial sum should be used (see appendix I). A theoretical investigation (2.46) has suggested that, in deep water, drag forces calculated using this approach will be conservative.

For currents that are approximately transverse to the wave direction the situation is uncertain and there is no information available as to how the wave orbital velocity and current should be combined.

\subsubsection{Eddy Shedding and Lift Forces}

There are indications in the literature $(2.11,2.17,2.19$, $2.20,2.47 \div 2.50)$ that transverse lift forces, of the same magnitude as drag forces, can be generated as a result of eddy shedding. If the frequency of vortex (eddy) shedding is sufficiently close to a natural frequency of the structure significant structural vibrations will occur. In steady currents the response and forcing under such conditions are interdependent (hydroelastic) and very large, potentially dangerous oscillations can build up) (Imnincharn jetty studies Wootton (2.49) and King (2.50)). Work is currently in progress on the wave forces on flexible conductor tubes, (2.51). 


\subsubsection{Wave Slamming and Impulsive Buoyancy}

It is generally recognised that horizontal members in the

splash zone are susceptible to fatigue due to buoyancy changes and wave slamming. Impulsive buoyancy is merely the sudden application of buoyancy loads as the member is submerged.

The dynamic response of the member should not be ignored since submergence is in general sufficiently rapid for appreciable dynamic stress amplification to ensue.

Wave slamming is due to impulsive pressures caused by impact of the member with the free surface. For the horizontal circular cylinder the slamming force can be estimated from

$$
F_{S}=\frac{1}{2} \rho C_{S} D W^{2} \text { per unit length }
$$

Because waves are rarely steeper than $H / \lambda \simeq 0.1$, slamming is predominantly a vertical force in the open ocean. Under breaking wave conditions, however, horizontal slamming will be significant. The velocity, $W$, in the above expression is the velocity of the water surface normal to itself and the resulting slamming force is in the same direction as the velocity.

Theoretically (2.52) $\mathrm{C}_{\mathrm{S}}$ is found to be $\pi$ for a circular cylinder but, since the slamming force is impulsive/in character, dynamic magnification must be considered. Under the most severe slamming conditions, where a wave impacts a cylinder simultaneously over its whole length, the full slamming load will be applied over a timescale of the order $0.1 \mathrm{~ms}$. Under these conditions the effective slamming coefficient (accounting for dynarnic response) can be near 6. Fortunately such events may be relatively infrequent since the timescales for oblique impact are considerably greater and dynamic response correspondingly smaller.

In recent experiments at NMI mean values of $\mathrm{C}_{\mathrm{S}}$ around 3.5 were found. This was consistent with the theoretical value anplified slightly by dynamic response. 
Impulsive buoyancy and slamming are, of course, experienced by other shapes. Slamming in particular, can be especially serious on large, flat areas.

\subsection{Wave Theory}

A wave theory appropriate to the wave conditions under consideration must be selected in order to evaluate wave orbit velocities and accelerations. Several such theories have been developed for various wave conditions. In relatively deep water the Stokes 5 th order theory (2.53) is commonly used to describe steep nonlinear waves. It involves extensive computation but as shown in figure 2.4 the resulting distributions of particle velocities and accelerations are not very different from those predicted by the relatively simple Airy linear theory (the latter being extended beyond the strict limits of linear assumptions to predict the velocities above the still water level). Correspondingly it has been found that in deep water, predictions of loading using Airy theory but integrating the forces up to the actual water surface (not as in strict linear thecry to the still water level) gives results which do not differ greatly from predictions based on Stokes 5 th. order theory. The stream function theory of Dean (2.54) is also available and arguably preferable in that, in most situations of engineering interest, it gives the best fit to the surface boundary conditions, and also can be used to describe an irregular wave. In shallow water, non-linear effects are significant and an appropriate theory (such as Cnoidal theory, which is discussed in reference 2.55) should be used for estimating the velocities and accelerations. A detailed discussion of the applicability of the various available wave theories has been given by Dean (2.30).

\subsection{Use of Morison's Equation and the Concent of Reliability}

Some papers studied in the literature survey $(2.16,2.56$ to 2.59$)$, criticised the Morison equation approach to evaluating wave forces and cast serious doubt on its validity as a design tool. Various reasons were given, such as the large errors in force evaluations which have arisen in some anulyses when usinf averaged values, and the complex intaraction 
between drag and inertia forces. It has been argued, however, (2.33), that the equation is useful in practical design conditions from an engineering point of view, if satisfactory results are obtained.

The meaning of 'satisfactory results' is open to personal interpretation, but clearly involves an assessment of reliability. The difficlity of assessing reliability of wave force coefficient values for use in Morison's equation has already been discussed but these uncertainties must be put into perspective with the consideration of reliability in the whole design procèss and this involves many factors unrelated to hydrodynamics. The concept and philosophy of risk and réliability analysis have been extensively discussed in references 2.60 and 2.61 and further investigation is warranted.

\section{USE OF DIFFRACTION ANALYSIS}

As stressed in both sections 1 and 2, when using Morison's equation it must be assumed that the diameter (or equivalent section dimension) of the structural member concerned is small enough in relation to wavelength to justify the assumption of uniform ambient acceleration and that there is no wave scattering or disturbance due to the local influence of neighbouring components. It should be noted however that Morison's equation may be applied to cylinders in groups as discussed in section 2.6.3. For guidance, the criterion diameter/wavelength $(D / \lambda)<0.2$ is recommended in reference 1.2 based on data in reference 3.1 and also on consideration of the range of wavelength over which it is reasonable to assume uniform acceleration by reference to the corresponding range of uniformity of wave surface slope. Evaluation of the inertia force term in Morison's equation also requires that the mass coefficient be known for the particular shape of structural component and corresponding direction of acceleration vector concerned. It may be helpful to mention here that mass coefficients for a viriety of simple geometrical shapes may be found for eximple in reference 3.? 
In the case of structures such as gravity type platforms or storage tanks involving components of relatively large section dimensions and complex shape it may be necessary to use methods based on diffraction theory for estimating the wave loads. Details of the theory and of a number of computer programs suitable for use in application to offshore.structures are documented in the literature. Theoretical details need not be discussed here but those interested may like to consult references 3.3 to 3.6 for example. A brief account will however be given of basic principles which should be understood if the method is to be used effectively. Attention will then be devoted to reviewing availability of suitable programs and associated data and guidance regarding reliability application and interpretation of results.

\subsection{Basic Principles}

Diffraction analysis models the fluid motion corresponding to a fixed or moving body in waves by determining functions describing a distribution of pulsating pressure points over the body surface which when superimposed on the known pressure field in the undisturbed incident wave satisfy all the boundary conditions. In practice the functions normally used satisfy only a linearised version of the free surface conditions and satisfy the body boundary conditions exactly only at a finite set of discrete points.

The forces and moments computed by integrating the pressure distribution over the body surface are conveniently expressed in two parts and hence written symbolically as

$$
F=F_{i}+F_{d}
$$

where $\mathrm{F}_{\mathrm{i}}$ is the contribution due to the undisturbed incident wave commonly known as the 'Froude Krylov' Component and $\mathrm{F}_{\mathrm{d}}$ is due to the disturbance caused by the pulsating pressure points and includes both wave scattering and the local disturbance corresponding to the added mass term in Morison's 
equation. When diameter is small enough in relation to wavelength so that the ambient acceleration $\dot{U}$ is approximately uniform and wave scattering is negligible, it may in fact be shown that

$$
\begin{array}{ll} 
& \mathrm{F}_{\mathrm{i}} \doteqdot \rho \mathrm{VU} \\
\text { and } & \mathrm{F}_{\mathrm{d}} \doteqdot \mathrm{k}_{\rho} \mathrm{VU} \text { where } \mathrm{k}=\mathrm{C}_{\mathrm{M}}-1 \\
\text { so that } & \mathrm{F} \doteqdot \mathrm{C}_{\mathrm{N}} \rho \mathrm{VU}
\end{array}
$$

In this case, the diffraction coefficient, $C_{h}$ commonly defined by

$$
C_{h}=\left(F_{i}+F_{d}\right) / F_{i}
$$

becomes equal to the inertia coefficient: $C_{M}$ so that

$$
F=C_{h} F_{i} \text { or } C_{M} \rho V U^{\circ}
$$

Diffraction analysis in these conditions is a way of computing the inertia coefficient.

\subsection{Availability of Programs}

The central problem of diffraction analysis is determination of the disturbance field. In some special cases, closed form solutions to this problem are known and the wave forces and moments can be computed directly from formulae expressed in terms of known functions. Such cases include vertical circular cylinders in waves both in deep water for which the solution may be found in reference 3.8 and in shallow water for which the theory and relevant formulae are documented in reference 3.9. For most practical structures calling for diffraction analysis however, it is necessary to use special computer programs into which the structure geometry is fed by finite element or facet modelling. A number of such programs have been developed and several are in use by the offshore industry. The status and availability of these are subject to continuing change and it must here 
suffice to present the accompanying summary table 3.1 listing programs which are documented in published papers known to the authors at the time of writing. This includes columns indicating program capability and availability of derived data and reference numbers identifying papers where detailed accounts may be found. For completeness some programs are listed which are not in fact based on diffraction theory but achieve the same results by simplified methods valid in some special cases.

\subsection{Reliability}

The reliability of diffraction theory and related methods of analysis has been extensively confirmed by comparisons with model experiments for a wide variety of simple geometric shapes and a comprehensive review of results from a number of different publications may be found in reference 3.10. The accompanying table 3.2 lists sources of data on reliability largely taken from this reference but with some additions. Special mention should be made of a paper, reference 3.29 describing results for a surface piercing vertical cylinder tested in multi-directional waves at the Hydraulics Research Station. In nearly all cases, the agreement between theory and experiment is good but there is relatively little published data relating to models of actual structures. Also only one paper (3.11) is known to the present authors which contains measured data from a full scale monolithic structure and the results are of a rather preliminary and inconclusive nature. It is therefore not yet possible to make any general quantitative assessment of reliability supported by full scale data. The agreement with model tests shown in figure 3.1 is reasonably typical of other comparisons listed in table 3.2. This is reassuring since diffraction is not normally considered subject to serious scale effects.

\subsection{Application}

Thrning now to the practical application of diffraction analysis the following discussion reviews briefly the nore significant lessons leaned from 
use of the NMI diffraction theory program. The original version of this documented in references 1.5 to 1.7 is only applicable to fixed structures but a later version briefly described in reference 1.8 has the capability for analysing moving bodies and for computing both the loads and motion responses for moored structures in waves.

\subsubsection{Fixed Structures}

Considering fixed structures, extensive experience covering a wide range of structure type has been gained from use of the program by IMI, by Lloyds Register of Shipping and by the industry as customers of a number of commercial computer bureaux to whom the program has been supplied on a basis ensuring some feedback of operating experience. Some of this has been reported in references 1.5 to 1.7 and there is only space here to draw attention to selected points of particular practical significance. The program can be applied, in theory, to almost any structural geometry but the reliability of the results will depend on the quality of the finite element modelling attainable within the limits of the store capacity of the computer concerned. The structure surface is modelled by a grid of polygonal plane area elements or facets, the design of which allows considerable scope for individual judgement. Guidance on modelling technique may be found in reference 1.6. Figure 3.2 illustrates the modelling of a gravity structure.

Much of the experience accumulated at NMI relates to gravity platforms and similar structures commonly involving a single large base supporting vertical towers which carry the platform and interest is usually concentrated on prediction of forces and overturning moments in extreme wave conditions (wave heights in the region of 30 metres and wavelengths of the order of 400 inetres or more). According to the criterion suggested in section 2, wave scattering can be neglected for these waves as far as the 
towers are concerned and also for the base unless its diameter is greater than $0.2 \mathrm{x}$ wavelength. It must be expected however that the local or 'added mass' disturbance due to the base will have some effect on the forces actin: on the lower parts of the towers. It is also important to appreciate that the pressure distribution across the top of the base, which may be significantly affected by the presence of the towers, contributes a component of moment which is in antiphase with the main overturning moment due to the towers and the pressures on the vertical surfaces of the base.

When deciding on the facet deployment, consideration must be given to the possible significance of these interactions between 'the towers and the base and indeed, in some cases, between the towers themselves. Guidance on this topic may be found in the references 1.5 to $1.7,3.11$ and 3.28 . If these interactions are reasonably small it may be decided that the components can be analysed separately using Morison's equation for the towers and diffraction theory for the base. In considering this decision the significance of the errors due to neglect of interaction must be weighed against the possible errors due to shortage of facets for modelling the base if the towers are included in the diffraction analysis. It must also be appreciated that for long tubular components a large number of facets is needed to achieve a modelling which is still approximate, whereas in this case calculations using an inertia coefficient as in Morison's equation can be based on exact potential flow theory.

The requirements for modelling of the base will depend on the complexity of its shape and some guidance may be found in reference 3.6. Here it is recommended that facets should preferably not be long and narrow and should have effective diameters no greater than about a seventh of a wavelength. It is also suggested that a finer mesh may be needed in the neighbourhood of high surface curvatures especially when these are concave. It is desirable where possible to test the resolution of the modelling by checkins the senitivity of the results to chances in the fineness of mesh. 
When the base approximates to some relatively simple geometric shape it may sometimes be possible to dispense with the computer program and apply

diffraction or inertiacoefficients derived from published data or adapted from previous computations using the formulae cited in section 3.1 above. Major economies can be achieved in this way, especially in systematic design studies where diffraction coefficients once computed may be accumulated for later use. A systematic compilation of data, derived in this way, for a range of vertical columns of varying height and section shape may for example be found in reference 1.7. Here it is noted that, on physical grounds, it is to be expected that the diffraction coefficients will be strongly . dependent on the ratio height/diameter (written as $h / 2 a$ ) referred to as the 'aspect ratio'... In the case of the horizontal force the formula

$$
C_{h}=1+0.075(h / 2 a)^{\frac{1}{2}}\left(1-0.3 k^{2} a^{2}\right)
$$

was found in fact to be a good fit to the data (here $k=2 \pi /$ wavelength and $\left.a=(\operatorname{section} \operatorname{area} / \pi)^{\frac{1}{2}}\right)$.

\subsubsection{M.oving Structures}

Because of the linearity of the diffraction analysis the loads on a structure executing prescribed motions in waves can be computed by adding the loads when fixed in waves to those when moving in still water. Computation of the fixed structure loads has already been discussed in the previous section. The basis for the moving structure computation is the same but with modification of the boundary conditions to accommodate the movement of the body surface and the results may be interpreted in a similar way. The Froude Krylov component of load is zero in this case but there is a component in phase with the structure acceleration which may be expressed in terms of an added mass and a component in phase with the structure velocity which represents the damping due to the radiated waves and is directly anitoesus to the wave scattering or diffraction term for a fixed structure a: discussed in the previous section. 
As explained in reference 1.8, the loads and motions of a structure moored or otherwise constrained in waves can be computed by solving the equations of motion. In formulating these the output from the diffraction analysis for the fixed body in waves provides the forcing function due to the incident wave which may be denoted by $F(t)$ while the output for the body moving in calm water supplies a component of added mass, $\delta \mathbb{M}$ and a damping coefficient $\zeta$; the stiffness function $s(t)$, which may vary with time, is derived from analysis of the mooring cable tensions or other constraint forces. In practice, equations covering the three translational and three rotational modes of motion and all relevant cross couplings may be needed. Considering, for simplicity, a single uncoupled mode of translation in a direction, $x$, the equation of motion for a structure of mass $M$ may be written on the basis of the foregoing as:

$$
(M+\delta M) \ddot{x}+\zeta \dot{x}+s(t) x=F(t)
$$

It must be noted that whereas $M$ is here the actual mass of the structure, the added mass component $\delta M$ is normally derived in terms of a coefficient relating it to the displacement $\rho V$. Thus writing

$$
\delta \mathrm{M}=\mathrm{k}_{1} \rho \mathrm{V}
$$

the added mass coefficient $k_{1}$ is derived from the diffraction analysis for the moving body in calm water by the formula

$$
\mathrm{k}_{1}=\mathrm{F}_{1} /(\rho \mathrm{V} \ddot{\mathrm{x}})
$$

where $F_{1}$ is the component of fluid force in phase with the acceleration of the structure, $\ddot{x}$. This component of added mass is not to be confused with the added mass term derived from the analysis for the fixed structure in waves which is included in $F(t)$ and is related to the fluid acceleration. Writing this as 


$$
-34-
$$

$$
\delta M_{0}=k_{0} \rho v
$$

the corresponding added mass coefficient $k_{0}$ is defined by

$$
k_{0}=F_{0}(t) /\left(\rho v \ddot{x}_{0}\right)
$$

where $F_{0}(t)$ is the component of fixed body force in phase with the fluid acceleration, $\ddot{x}_{0}$.

Considering the damping coefficient, this may be written as

$$
\begin{gathered}
\zeta=k_{2} \rho V \\
\text { where } k_{2}=F_{2} /(\rho V \dot{x})
\end{gathered}
$$

and $\mathrm{F}_{2}$ is the component of moving body force in phase with the structure velocity $\dot{x}$.

Systematic data on values of the added mass and damping coefficients for moving box shaped bodies may be found in reference 3.13. As noted in table 3.1, this reference also includes data on drift forces which are steady components of wave force and are of second order but may be computed in terms of the squares of velocities available from the first order solution. These forces are small relative to the amplitudes of the fluctuating forces but may be significant in some cases, for example, in relation to dynamic positioning.

\section{THE INFLUENCE OF MARINE ROUGHNESS ON LOADING}

Marine growths and corrosion increase the fluid dynamic loads on of $f$ shore structures in two ways. The accumulation of growth leads to an increase in the volumetric displacement $\left(V \alpha D^{2}\right)$ and frontal area $(A \alpha D)$ due to the increase in diameter. Consequently there are increased inertia and drag loads purely due to changes in bulk geometry. At the flow Reynolds numbers encountered in practice $\left(10^{5}<\mathrm{R}_{\mathrm{e}}<10^{8}\right)$, the roughening effects of growth and corrosion 
lead to increased drag coefficients and consequently to increases in loading over and above that due to increased diameter.

\subsection{Marine Roughness}

Galler $(4.1)$ and Houghton $(4.2,4.3)$ have described the various forms of fouling to which marine structures are subjected. From a fluid dynamic viewpoint it is probably necessary to distinguish between rigid roughress (such as rust, scale, barnacles and mussels) and those which are flexible (such as seaweed and sea-anemones) because the interaction between the flow and the growth/roughness is likely to be different if the growth responds dynamically to fluid forces. It is thought that in the persistently severe weather conditions of the northern North Sea the marine growths are, at least initially, likely to be of the more tenacious rigid type. In the southern North Sea the problem is largely one of gross accumulations of mainly flexible growths.

\subsection{Roughness Definition}

In general, the characterisation of roughness should express the spatial distribution, size and shape of roughness excrescences. It is, however, found that sharp-edged randomly distributed roughness can be characterised by an average roughness height, $k_{r}(4.4)$. Rigid marine growths can be characterised in this way provided they are not sparse, i.e. comprise relatively closely packed excrescences. For reasons which will become clear later on in this section, it is not necessary to know the roughness height to any great precision so that a reasonable estimate of the average height of protrusion is, in most cases, adequate.

With reference to the drag of circular cylinders, the relevant roughness parameter is the relative roughness defined as the ratio of the roughness height to the cylinder diameter $\left(k_{r} / D\right)$. 


\subsection{Influence of Roughness on Cylinder Drag}

tow noss feneraliy causes increased rates of boundary layer growth and

higher skin friction. On slender bodies, like ships, it is mainly the increase in skin friction which is responsible for the increased drag associated with fouling $(4.5,4.6)$. However when the thickened boundary

layers are rapidly decelerated their behaviour is markedly different

to those over smooth cylinders and they separate earlier. Consequently the pressure distribution over the cylinder is changed and higher "form" or pressure drag results.

In figure 4.1 the effects of roughness upon the drag of cylinders in steady flow is shown graphically in the results obtained recently at NMI (1.19). Roughness clearly has three main effects:-

(1) The critical Reynolds number, where the drag coefficient falls steeply with increasing Reynolds number, occurs progressively earlier as roughness $\left(\mathrm{k}_{\mathrm{r}} / \mathrm{D}\right)$ increases.

(2) The minimum drag coefficient (drag trough) inereases with increase in roughness $\left(k_{r} / D\right)$.

(3) The drag coefficient at high Reynolds numbers is higher than for smooth cylinders.

These effects were first noted by Fage and Warsap (4.8), whose experiments did not attain Reynolds numbers at which the drag coefficient became constant, unlike those of Achenbach (4.9). From a compendium of the NMI results (1.10) and those of Szechenyi (4.10), and Achenbach (4.9) and Wong (given in the discussion of $(1.10))$ the curve of the drag coefficients appropriate to high Reynolds numbers against relative roughness $\left(k_{r} / D\right)$ can be plotted (figure 4.2 ). Note that the values of $C_{D}$ quoted are average values in the Reynolds number rarges quoted and that for $\mathrm{k}_{\mathrm{r}} / \mathrm{D}<10^{-3}$ the variations within the range are not insignificant. 
In figure 4.2 there are clearly three regions of roughness having distinctly different characteristics:

(i) For $k_{r} / D<2 \times 10^{-3}$, the drag coefficient, $C_{D}$, decreases with decreasing roughness to the value appropriate to smooth cylinders $(0.6-0.7)$.

(ii) For $2 \times 10^{-3}<k_{r} / D<10^{-2}, \quad C_{D}$ is constant at approximately 1 .

(iii) For $k_{r} / D>10^{-2}, \quad C_{D}$ increases with increasing $k_{r} / D$. The highest $C_{D}$ observed was 1.25 at $k_{r} / D \simeq 5 \times 10^{-2}$.

Since the rates of change of $C_{D}$ with $k_{r} / D$ are never particularly large the accuracy of $k_{r} / D$ is not crucial. All the above results are for steady flow; recent tests at NMI (4.11) have shown that roughness has similar effects in wave flows at Keulegan-Carpenter numbers as low as 15. and Reynolds numbers around $10^{5}$.

These findings are reinforced at high Reynolds numbers by the Bass Strait results, quoted by Wong (4.7) where $C_{D}$ values near 1 were found. Recently Sarpkaya (2.20) has found that roughness increases $C_{D}$ up to as much as 1.7 in simple harmonic conditions; there remains, however, some doubt as to the direct application of such results to wave flows.

\subsection{Allowing for Roughness in Design}

- In order to calculate the effects of marine growth on loadings the designer must estimate

(a) the thickness of growth (up to $20 \mathrm{~cm}$ in some areas, formed at a peak rate of $2-3 \mathrm{~cm} / \mathrm{month})$, and hence the increase in diameter and volume.

(b) the effective roughness height, $\mathrm{k}_{\mathrm{r}}$, and hence the relative roughness $\mathrm{k}_{\mathrm{r}} / \mathrm{D}$. 
The increased $C_{D}$ value for steady flow may be obtained from figure 4.2, but it is emphasised that, as discussed in section 2.1, care must be taken in applying steady flow results to wave conditions. It should also be recalled that the wave force coefficient values suggested in figure 2.1 apply to smooth cylinders. In practice roughness will affect the coefficient values (figure 2.1) and their reliability. In particular, the value of $C_{D}$ at postcritical Reynolds numbers is likely to be higher and values of about 0.8 to 1.0 are suggested as appropriate for average, in-service conditions, the values increasing with the degree of roughness. The degree of uncertainty in $C_{M}$ and $C_{D}$ values modified to allow for roughness effects in waves is largely unknown and is probably less than that suggested in figure 2.1 for smooth cylinders.

\section{CONCLUDING REMARKS}

The aim of this paper has been to undertake a critical evaluation of methods and associated data documented in the literature for estimating fluid loading on offshore structures, which it is hoped will be a useful working reference for designers. The authors wish to emphasise that their assessments of reliability are made from a fluid mechanics point of view and they do not claim competence to advise on the overall design process which contains many other factors. They also recognise that designers will wish to make their own evaluations of methods and data which they use and they have taken pains to identify the sources for all the information and advice offered.

The main concern has been with evaluation of data in the literature on wave force coefficients for use in Morison's equation and section 2 includes tabular summaries of the data sources and of the suggested values for drag and inertia coefficients systematically stratified in terms of the two key parameters, Keulegan-Carpenter number and Reynolds number, and accompanied by assessments of reliability based on information in the references cited. The associated text discusses some of the problems involved in applying 
Morison's equation to actual structures and offers some advice on the choice of method for specifying the associated wave conditions. It also includes some comments on the meaning of 'reliability' in the context of design und notes that the reliability of wave force predictions must be set into perspective with all the other factors in the whole design process.

Section 3 reviews methods available for using diffraction analysis and much of the material here is based on experience at NMI in the development and operation of a computer program written for this purpose and already extensively used by the offshore industry. The need for such methods arises in cases such as gravity type structures and tethered buoyant platforms involving monolithic components with large section dimensions or complex shapes for which the inertia coefficients may not be known. It is noted that it is often desirable to combine diffraction analysis with use of Morison's equation and the importance of understanding the physical interpretation of the corresponding results is emphasised. An account is also given of the special problems involved in the case of moving bodies such as tethered buoyant platforms.

Section 4 discusses very briefly the question of the effect of marine roughness and refers to some work at NMI indicating that roughness can have a very substantial effect on the drag coefficient both in steady flow and in waves.

A general conclusion of the paper is that, although the data available in the literature is very plentiful, there are, nonetheless, stili many serious uncertainties regarding the reliability of fluid loading estimates. A major source of doubt arises from the scale effects on drag, which are very large, coupled with a shortage of reliable full scale drag data in waves. The authors believe that in the future more emphasis must be placed on collection of data fron structures in the sea and other experiments in 
which conditions corresponding to critical and postcritical Reynolds rumbers can be realised. Feedback of data from actual operational structures should be the surest way of establishing and improving the reliability of loading predictions.

\section{ACKNOWLEDGEIMENTS}

The authors are indebted to the Director of the National Maritime Institute and the Director of Research of the British Ship Research Association for permission to publish this paper. They would also like to acknowledge that the work was undertaken as part of the programme of research recommended by the Offshore Structures Fluid Loading Advisory Group (OSFIAG) established by the Department of Industry and subsequently-funded by the Department of Energy through the Offshore Energy Technology Board. 


\section{NOMENCLATURE}

a

A

$\mathrm{C}_{\mathrm{D}}$

$\mathrm{C}_{\mathrm{h}}$

$\mathrm{C}_{\mathrm{M}}$

$\mathrm{C}_{\mathrm{S}}$

d

D

F

$F_{0}$

$F_{1}$

$\mathrm{F}_{2}$

$F^{\prime}$

$\mathrm{F}_{\mathrm{D}}$

$\mathrm{F}_{\mathrm{I}}$
Radius of columnar structure (or equivalent dimension) or semi-orbit width of wave particle horizontal travel.

Projected frontal area of structure.

Drag coefficient.

Diffraction coefficient.

Inertia coefficient.

Slamming coefficient

Water. depth.

Diameter of cylinder (or equivalent dimension).

Horizontal fluid force.

Component of force in phase with acceleration of fluid.

Component of force in phase with acceleration of structure.

Component of force in phase with velocity of structure.

Horizontal wave force on a vertical cylinder.

Drag force.

Inertia force. 
$\mathrm{F}_{\mathrm{S}}$

$\mathrm{F}_{\mathrm{d}}$

$\mathrm{F}_{\mathrm{i}}$

g

h

$\mathrm{H}$

$\mathrm{k}$

$k, k_{0}, k_{1}, k_{2} \quad$ Added mass coefficients.

$k_{r}$

M

$\mathrm{N}_{\mathrm{K}}$

$\mathrm{R}$ e

S

$s(t)$

t

$\mathrm{T}$

Wave height.

Wave number.

Mass of structure.

Reynolds number.

Stiffness function.

Time.

Wave Period.
Wave slamming force per unit length.

Force due to local disturbance and wave scattering.

Undisturbed incident (Froude-Krylov) wave force.

Acceleration due to gravity.

Height of columnar structure.

Height of surface roughness excrescence.

Keulegan-Carpenter nunber.

Centre to centre spacing between adjacent cylinders. 
Horizontal component of wave particle orbital velocity. Amplitude of horizontal oscillatory velocity. $d t$

Slamming velocity of water.

\section{Distance co-ordinate.}

$$
\text { Damping coefficient. }
$$




\section{SECTION 1}

1.1 MORISONi, J.R., O'BRIEN, M.P., JOHNSON, J.W. and SCHAAF, S.A. "The force exerted by surface waves on piles". Petroleum Trarsactions AINE Vol. 189, 1950.

1.2 HOGBEN, N. "Fluid loading on of shore structures, a state of art appraisal: wave loads". Maritime Technology Morcgraph No. 1, published by the Royal Institution of Nav 1 Arch-tects, Novemker 1974.

1.3 KEULEGAN, G.H. and CARPENTER, L.H. "Forces on cylinders and plates in an oscillating fluid". Journal of the National Bureau of Standards Vol. 60, No. 5, pp 423-440, May 1958.

1.4 "A critical evaluation of the data on wave force coefficients". Contract Report No. W 278 by tre British Ship Research Assciation, August 1976.

1.5 HOGBEN, N. and STANDING, R.G. "Wave loads on large bodies". Proc. International Symposium on Dynamics of Marine Vehicles arid Structures in Weves, published by Institution of Mechanical Engineers, 1974.

1.6 HOGBEN, N., OSBORNE, J. and STANDING, R.G. "Wave loading on offshore structures - theory and experiment". Proc. Symposium on Ocean Engineering, published by Royal Institution of Naval Architects. November 1974 .

1.7 HOGBEN, N. and STANDING, R.G. "Experience in computing wave loads on large bodies". Paper OTC 2189 offshore Technology Conference, Houston, May 1975.

1.8 HOGBEN, N. and STANDING, R.G. "Review of progress part II research related primarily to gravity type structures and tetherei buoyant platforms", Proc. NPL Seminar on Fluid Loading of offshore Structures, September 1975.

1.9 RICHARDSON, J.R. and PINTO, U.H. "Progress report on tethered buoyant platforms, Part I". NPL Maritime Science Division Report No. 134, September 1975.

1.10 MILLER, B. L. "The hydrodynamic drag of roughened cylinders". Spring Meeting, Royal Institution of Naval Architects, Paper No. 9, 1976. 


$$
-45-
$$

1.11 Proceedings of NPL Seminar on Fluid Loading of Offshore Structures, September 1975 .

1.12 HOGEEN, N. "Wave loading of of fshore structures" Prcc. Behaviour of offshore Structures Conference (BOSS 176), Trondheim, Avgust 1976. 
2.1 AAGAARD, P.M. and DEAN, R.G. "Wave forces: data analys is and engineerin€ calculation method". Offshore Technology Conference, Paper OTC 1008, Houston, Texas, 1969.

2.2 BRETSCHNEIDER, C.L. " "Probability distribution of wave forces". Journal of the Waterways and Harbors Division. ASCE, Vol. 13, No. WW 2, May 1967.

2.3 CHAKRABAFTI, S.K. and TAM, W.A. "Gross and local wave loads on a large vertical cylinder - theory and experiment". Offshore Technology Conference, Paper OTC 1818, Houstor, Texas, 1973.

2.4 CHAKRABARTI, S.K., TAM, W.A. and WOLBERT, A.L. "Wave forces on a randomly orientated tube". Offshore Technology Conference, Paper OTC 2190, Houston, Texas, 1975.

2.5 EVANS, D.J. "Analysis of wave force data". Offshore Technology Conference, Paper OTC 1005, Houston, Texas, 1969.

2.6 GARRISON, C.J., TORUM, A., IVERSON, C., LEIVSETH, S. and EBBESMEYER, C.C. "Wave forces on large volume structures - a comparison between theory and model tests". Offshore Technology Conference, Paper OTC 2137, Houston, Texas, 1974.

2.7 GRACE, R.A. and CASCIANO, F.M. "Ocean wave forces on a subsurface sphere". Journal of the Waterways and Harbors Division. ASCE, Vol. 95, No. WW 3, August 1969.

2.8 HUDSPETH, R.T., DALRYMPLE, R.A. and DEAN, R.G. "Comparison of wave forces computed by linear and stream function methods". Offshore Technology Conference, Paper OTC 2037, Houston, Texas, 1974.

2.9 JEN, Y. "Laboratory study of inertia forces on a pile". Journal of the Waterways and Harbors Division, ASCE, Vol. 94, No. WW 1, February 1968.

2.10 JOHNSON, E.R. "Horizontal forces due to waves acting on large vertical cylinders in deep water". Transactions ASME - 1973.

2.11 KEULEGAN, G.H. and CARPENTER, L.H. "Forces on cylinders and plates in oscillating fluid". Journal of the National Bureau of Standards, Vol. 60, No. 5, May 1958. 
2.12 KIM, Y.Y. and HIBBARD, H.C. "Analysis of simultaneous wave force and water "particle velocity measuremerts". Offshore Technolosy Conference, Paper OTC 2192, Houston, Texas, 1975.

2.13 MERCIER, J. "Large amplitude cscillations of a circular cylinder in a low speed stream". Dissertation: Stevens Institute of Techriology, 1973.

2.14 MORISON, J.R., O'BRIEN, M.P., JOHNSON, J.W. and SCHAAF, S.A. "The forces exerted by surface waves on piles". Petroleum Transactions, AIME, Vol. 189, 1950.

2.15 OBRIEN, M.D. and MORISON, J.R. "Ihe forces exerted by waves or objects". Transactions of the American Geophysical Unior, Vol. 33, No. 1, February 1952.

2.16 PAAPE, A. and BREUSERS, H.N.C. "The influence of pile dimension on forces exerted by waves". ASCE Proceedings, 10th Coastal Engineering Conference, Chapter 48, 1967.

2.17 RANCE, P.J. "Wave forces on cylindrical members of structures". Hydraulics Research Station Annual Report, 1969.

2.18 REID, R.0. "Correlation of water level variations with wave forces or it vertical pile for non-periodic waves". Proceedings 6th Coastal Engineering Conference, Gainsville, Florida. Council for Wave Research, Berkeley, California, 1958, pp 749-786.

2.19 SARPKAYA, T. and TUTER, 0. "Periodic flow about bluff kodies, part I, Forces on cylinders and spheres in a sinusoidally oscillating fluid". Naval Postgraduate School, Monterey, California - report NPS 59SL74C91, September 1974.

2.20 SARPKAYA, T. "Vortex shedding and resistance in harmonic flow about smooth and rough cylinders". Proceedings, Behaviour of of fshore Structures, (BOSS 176), Trondheim, August 1976.

2.21 SEKITA, K. "Laboratory experiments on wave and current forces a.cting on a fixed platform". Offshore Technology Conference, Paper OTC 2191, Houston, Texas, 1975.

2.22 SHANK, G.E. and HER [CH, J.B. "Forces due tc waves on submered structures". Texas A\&I Report SG70212. Coastal and Ocean Engrineering Report No. 123. College Station, T'xas, May $19 \%$. 


$$
-48-
$$

2.23 SUSBIELLES, G. G., VAN DEN BUNT, J.R., DELENIL, G. and MICHEL, D. "Wave forces on pile sections due to irregular and regular waves". Offshore Technology Conference, Paper OTC 1379, Houston, Texas, 1971.

2.24 WHEELER, J.D. "Method of calculating forces produced by irregular waves". Offshore Technology Conference, Paper OTC 1006, Houston, Texas, 1969.

2.25 WIEGEL, R.L., BEEBE, K.E. and MOON, J. "Ocean Wave forces on circular cylindrical piles". Journal of the Hydraulics Division, ASCE, Vol. 83, No. HY2, April 1957.

2.26 WILSON, B.W. "Analysis of wave forces on a 30-inch diameter pile under confused sea conditions". U.S. Army, Coastal Engineering Research Centre, Technical Memorandum No. 15, October 1965.

2.27 HOERNER, S.F. "Fluid Dynamic Drag", published by the author, 1958.

2.28 DELANY, N.K. and SORENSEN, N.E. "Low speed drag of cylinders of various shapes". U.S. National Advisory Committee for Aeronautics, Technical note 3038, Nov. 1953.

2.29 ROSHKO, A. "Experiments on the flow past a cylinder at very high Reynolds numbers". Journal of Fluid Mechanics. Vol. 10., No. 3, May 1961, pp 345-356.

2.30 DEAN, R.G. "Relative validities of water wave theories". Journal of the Waterways and Harbors Division, ASCE, Vol. 96, No. WW 1, February 1970.

2.31 BORGMAN, L.E. "Spectral analysis of ocean wave forces on piling". Journal of the Waterways and Harbors Division, ASCE, Vol. 93, No. WW 2, May 1967.

2.32 BORGMAN, I.E. "Ocean wave simulation for engineering design". Journal of the Waterways and Harbors Division, ASCE, Vol. 95 , No. WW 4, November 1969.

2.33 WIEGEL, R.L. "Waves and their effects on pile supported structures". Symposium on Wave Action, Delft, 1969.

2.34 DFAN, R.G. "Methodology for evaluating suitability of wave and force data for determining drag and inertia forces". Proceedings, Behaviour of offshore Structures, (BOSS 16), Trondheim, Aurust 1976. 
2.35 PIERSON, W.J. and HOLMES, P. "Irregular wave forces on a pile". Journal of ,the Waterway, Harbors and Coastal Engineering Division, ASCE, Vol. 91, November 1965.

2.36 GOLDSTEIN, S. Modern developments in fluid dynamics". Vol. 2, p. 439, Clarendon Press, Oxford, 1957.

2.37 ENGINEERING SCIENCES DATA UNIT (ESDU). Data sheet 75011. The following are also relevant to steady flow loadings: 71012, 70013, 70014.

2.38 ARITA, Y., FUJITA, M. and TAGAYA, K. "A study of the force of tidal currents acting on a multi-tubular column". Offshore Technology Conference, Paper OTC 1815, Houston, Texas, 1973.

2.39 MILLER, B.L. and MATTEN, R.B. "A technique for the analysis of wave loading data obtained from model tests". NPL Report Mar Sci R136, June 1976.

2.40 SACHS, P. "Wind forces in engineering". Pergamon, 1972.

2.41 DALTON, C. and HELFINSTINE, R. A. "Potential flow past a group of circular cylinders". ASME paper no. 71-FE-18. May 1971.

2.42 GIENNY, D.E. "A review of flow around circular cylinders, stranded cylinders and struts inclined to the flow direction". Mechanical Engineering Note, 284, Department of Supply, Australian Defence Scientific Service Aeronautical Research Laboratories, October 1966.

2.43 SCHILLER, H.C. "Wave forces on a submerged horizontal cylinder". Thesis, Naval Postgraduate School, Monterey, California. Report No. AD 727691, June 1971.

2.44 WILSON, B.W. and REID, R.O. "Wave force coefficients for offshore pipelines". Journal of the Waterways, Harbors and Coastal Engineering Division, ASCE Vol. 89, No. WW 1, February 1963.

2.45 LITTLEJOHNS, P.S.G. "Current induced forces on submarine pipelines". Hydraulics Research Station, INT 138, September 1974.

2.46 DALHYMPLE, R.A. Models for non-linear water waves on shear currents". Offshore Technology Conference, Paper OTC 2114, Houston, Texas, 1974 . 
2.47 BIDDE, D. "Laboratory study of lift forces on circular piles". Journal of the Waterways, Harbors and Ccastal Engineering Division, ASCE Vol. 97, No. WW 4, November 1971.

2.48 WIEGEL, R.L. and DELMONTE, R.C. "Wave induced eddies and "lift" forces on circular cylinders". Ninth symposium on Naval Hydrodynemics, Paris, 1972.

2.49 WOOTTON, L.R., SAINSBURY, R.N., WARNER, M.H. and COOPER, D.H. "The flow induced oscillations of piles". National Physical Laboratory, Aero Special. Report 025, January 1969.

2.50 KING, R. "The stability of piles in flowing water". BHRA TN 1191, May 1973.

2.51 VERLEY, R.L.P. "Study of wave forces on conductor tubes". BHRA progress report to the Department of Energy, August 1975.

2.52 VON KARMAN, T. and WATTENDORF, P.L. "The impact of seaplane floats during landing". NACA TN 332, 1929. (The theoretical value of $\mathrm{C}_{\mathrm{S}}$ for a cylinder can be calculated according to principles presented in this paper).

2.53 SKJELBREIA, L. and HENDRICKSON, J.A. "Fifth order gravity wave theory". Proceedings of Seventh Conference on Coastal Engineering. Council on Wave Research. The Engineering Foundation, 1961. Ch. 10, pp 184-196.

2.54 DEAN, R.G. "Stream function representation of non-linear ocean waves". Journal of Geophysical Research. Vol. 70, No. 18, September 1965.

2.55 WIEGEL, R.L. "Oceanographical Engineering". Prentice Hall, 1964, pp 40-53.

2.56 CROOKE, R.C. "Re-analysis of existing wave force data on model piles". U.S. Corps of Engineers Beach Erosion Board. Technical Memorandum No. 71, 1955.

2.57 IVERSEN, H.W. and BALENT, R. "A correlating modulus for fluid resistance in accelerated flow": Journal of Applied Physics, Vol. 22, No. 3, March 1951.

2.58 DALTON, C. and HAMANN, F. "The forces on a cylinder oscillating sinusoidally in water". ASME Paper no. 71-Pet-2, 1971. 
2.59 KELM, S.R. "Fluid resistance to cylinders in accelerated motion". Journal of 'the Hydraulics Division, ASCE, Vol. 82, No. HY6, December 1956.

2.60 SCHUELLER, G.I. "On the risk assessment of offshore structures". Offshore Technology Conference, Paper OTC 2334, Houston, Texas, 1975.

2.61. BEA, R.G. "Development of safe environmental criteria for offshore structures". Oceanology International. Brighton 1975.

2.62 SARPKAYA, T. "In-line and transverse forces on smooth and sandroughened cylinders in oscillatory flow at high Reynolds numbers". Naval Postgraduate School, Montery, NPS-69SL76062, June 1976.

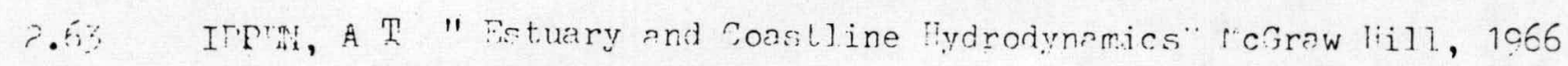




\section{SECTION 3}

3.1 CHAKRABARTI, S.K. and TAM, W.A. "Gross and local wave loads on a large vertical cylinder - theory and experiment" Paper OTC 1818, Offshore Technology Conference, Houston, 1973.

3.2 MYERS, J.J., HOLM, C.H. and MACALLISTER, R.G. . "Handbook of ocean engineering" McGraw Hill, 1969.

3.3 JOHN, F. "On the motion of floating bodies part II" Communications in Pure and Applied Maths Vol. 3, 1950.

3.4 WEHAUSEN, J.V. and LAITONE, E.V. "Surface waves". Encyclopaedia of Physics, S. Flugge, ed., Vol. 9, Springer-Verlag, Berlin, 1960.

3.5 NEWMAN, J.N. "Diffraction of water waves". Applied Mechanics Reviews Vol. 25, No. 1, January 1972, pp 1-7.

3.6 HESS, J.L. and SMITH, A.M.O. "Calculation of potential flow about arbitrary bodies". Progress in Aeronautical Sciences, Vol. 8, pp 1-138, 1967.

3.7 FRANK, W. "Oscillations of cylinders in or below the free surface of deep fluids". Naval Ship Research and Development Center Report No. 2375, 1967.

3.8 HAVELOCK, T.H. "The pressure of water waves on a fixed obstacle" Proceedings of the Royal Society. A175, pp 409-421, 1940.

3.9 MACCAMY, R.C. and FUCHS, R.A. "Wave forces on piles: a diffraction theory". Beach Erosion Board Technical Memorandum No. 69, 1954.

3.10 CHAKRABARTI, S.K. "Wave forces on submerged objects of symmetry". ASCE Waterways and Harbors Division, Vol. 98, 1972.

3.11 BROGREN, E., SODERSTROM, J., SNIDER, R. and STEVENS, J. "Field data recovery system, Khazzan Dubai No. 3", Paper OTC 1943, Offshore Technology Conference, Houston, 1974.

3.12 LEBRETON, J.C. and CORMAULT, P. "Wave action on slightly immersed structures, some theoretical and experimental considerations", Proc. Symposium on Research on Wave Action, Vol. 4, Delft, 1969.

3.13 FALTINSEN, O. and MICHEiLSFN, F.C. "Motions of large structures in waves at zero Froude number". Proc. International Symposium on Dynamics of Marine Vehicles and Structures in Waves, Published by Institution of Mechanical Einerineers", 1974. 
3.14 BAI, K.J. and YEUNG, R.W. "Numerical solutions to free surface flow problems". Proc. 10th ONR Symposium on Naval Hydrcdynamics MIT, 1974.

3.15. CHEN, H.S. and MEI, C.C. "Oscillations and wave forces in a man made harbor in the open sea". Proc. 10th ONR Symposium on Naval Hydrodynamics MIT, 1974.

3.16 GARRISON, C.J. "Dynamic response of floating bodies" Paper OTC 2027, Offshore Technology Conference, Houston, 1974.

3.17 MAEDA, H. "Hydrodynamic forces on a cross section of a stationary structure". Proc. International Symposium on Dynamics of Marine Vehicles and Structures in Waves, published by Institution of Mechanical Engineers, 1974.

3.18 VAN OORTIERSSEN, G. "Some aspects of very large offshore structures". Proc. 9th ONR Symposium on Naval Hydrodynamics, Paris, 1972.

3.19 ST DHNIS, M. "Or. the motions of oceanic platforms". Proc. International Symposium on Dynamics of Marine Vehicles and Structures in Waves, published by Institution of Mechanical Engineers, 1974.

3.20 BLACK, J.L. "Wave forces on vertical axisymmetric bodies" Journal of Fluid Mechanics, Vol. 67, Part 2, pp 369-376, 1975.

3.21 BLACK, J.L., MEI, C.C. and BRAY, M.C.G. "Radiation and scattering of water waves by rigid bodies". Journal of Fluid Mechanics, Vol. 46, Part 1, pp 151-164, 1971.

3.22 GARRETT, C.J.R. "Wave forces on a circular dock", Journal of Fluid Mechanics, Vol. 46, Part 1, pp 129-139, 1971.

3.23 GRAN, S. "Wave forces on submerged cylinders". Paper OTC 1817 Offshore Technology Conference, Houston, 1973.

3.24 KOKKINOWRACHOS, K. and WILCKENS, H. "Hydrodynamic analysis of cylindrical offshore oil storage tanks". Paper OTC 1944 offshore Technology Conference, Houston, 1974.

3.25 MILGRAM, J.H. and HALKYARD, J.E. "Wave forces on large objects in the sea". Journal of Ship Research, pp 115-124, June 1971. 
3.26 OHKUSU, M. "Hydrodynamic forces on multiple cylinders in waves". Proc. International Symposium on Dynamics of Varine Vehicles and Structures in Waves, published by Institution of Mechanical Engineers, 1974.

3.27 BOREEL, L.J. "Wave action on large offshore structures". Proceedings of the Institution of Civil Engineers Conference on Offshore Structures, London 1974.

3.28 GARRISON, C.J., TфRUM, A., IVERSEN, C., LEIVSETH, S. and EBBESMEYER, C.C. "Wave forces on large volume structures - a comparison between theory and model tests" paper OTC 2137 offshore Technology Conference, Houston, 1974.

3.29 HUNTINGTON, S.W. and THOMPSON, D.M. "Forces on a large vertical cylinder in multidirectional waves". Paper OTC 2539, offshore Technology Conference, Houston, Texas, 1976. ..

3.30 MILLER, B.L. "Wave slamming loads on horizontal, circular elements of offshore Structures". Paper No 5, RINA Spring Meetings, April 1977.

3.31 GARRISON, C.J. and SNIDER, R.H. "Wave Forces on Large Submerged Tanks". Texas A and M University, Sea Grant publication No 210, COE Report No 117, 1970.

3.32 BRATER, E.F., MCNOWN, J.S. and STAIR, L.D. "Wave forces on submerged structures". J. Hyd. Div. ASCE Paper 1833, 84, HrG, Nov. 1958. 


\section{SECTION 4}

4.1 GALIER, S.R. "Boring and fouling", pp 7-12, 7-19 in "ilandbook of Ocean and Underwater Engineering" McGraw Hill, 1969.

4.2 Houghton, D.R. "Mechanisms of marine fouling". Proc. 1st International Biodeterioration Symposium, Southampton, September 1968.

4.3 HOUGHTON, D.R. "Foul play on the ship's bottom". New Scientist, 3 December 1970.

4.4 SCHLICTING, H. "Boundary layer theory". McGraw Hill, 1960.

4.5 LACKENBY, H. "The resistance of ships with special reference to skin friction and hull surface condition". 34th Thomas Lowe Gray Lecture, Institute of Mechanical Engineers, Jan. 1962.

4.6 TELFER, I.E. "Some aspects of the external maintenance of tankers". The Naval Architect, July 1972.

4.7 WONG, F.Y.F. "Preliminary survey of the drag coefficient of circular cylinders". Lloyds Register of Shipping Report, June 1973.

4.8 FAGE, A. and WARSAP, J.H. "The effects of turbulence and surface roughness on the drag of a circular cylinder. ARC R and M 1283, October 1929.

4.9 ACHENBACH, E. "Influence of surface roughness on the cross-flow around a circular cylinder". Journal of Fluid Mechanics, Vol. 46, part 2, 1971, pp 321-335.

4.10 SZECHENYI, E. "Supercritical Reynolds number simulation for twodimensional flow over circular cylinders". Journal of Fluid Mechanics, Vol. 70, part 3, 1975, pp 529-542.

4.11 MATTEN, R.B. "The Influence of surf $x$ roughness on the drag of circular cylinders in waves". Paper OTC 2902 Offshore Technology Conference. Houston, Texas, 1977.

4.12 SARPKAYA, T. "Vortex shedding and resistance in harmonic flow about smooth and rough circular cylinders at high Reynolds numbers". Naval. Postgraduate School, Monterey, NPS-59SL76021, February 1976. 


\section{APPENDIX I}

$\frac{\text { Definition of the Keulegan-Carpenter Number, }}{\mathrm{N}_{\mathrm{K}} \text {, and its Relationship to Force Regime }}$

Keulegan-Carpenter number $N_{K}$ is defined in reference 1.3 as

$$
\mathrm{N}_{\mathrm{K}}=\mathrm{U}_{\mathrm{M}^{\mathrm{T}} / \mathrm{D}}
$$

Its significance in the context of this paper is that it is a measure of the relative importance of drag and inertia force. The ratio of the maximum drag force, 'F Dmax' to the maximum inertia force, $F_{\text {Imax' }}$ ' is given by the Morison equation:

$$
\frac{F_{D \text { max }}}{F_{I \max }}=\alpha=\frac{2}{\pi} \frac{C_{D}}{C_{M}} \frac{U_{M}^{2}}{U_{M}} \frac{1}{D}
$$

For a sinusoidal flow $U=U_{M} \cos \frac{2 \pi t}{T}$

$$
\dot{\mathrm{U}}_{\mathrm{M}}=\frac{2 \pi \mathrm{U}_{\mathrm{M}}}{\mathrm{T}}
$$

whence $\alpha=\frac{\mathrm{C}_{\mathrm{D}}}{\mathrm{C}_{\mathrm{M}}} \cdot \frac{1}{\pi^{2}} \cdot \frac{\mathrm{U}_{\mathrm{M}}^{\mathrm{T}}}{\mathrm{D}}=\frac{\mathrm{C}_{\mathrm{D}}}{\mathrm{C}_{\mathrm{M}}} \frac{\mathrm{N}_{\mathrm{K}}}{\pi^{2}}$

When a current of velocity ${ }{ }_{C}$ ' parallel to $U_{M}$ ' is flowing

$$
\alpha_{C}=\frac{C_{D}}{C_{M}} \cdot \frac{N_{K}}{\pi^{2}} \cdot\left(1+\frac{U_{C}}{U_{M}}\right)^{2}=\alpha\left(1+\frac{U_{C}}{U_{M}}\right)^{2}
$$

At the still water level in deep water waves, $U_{M}=\frac{\pi H}{T}$ and

$$
\begin{aligned}
& \alpha=\frac{C_{D}}{C_{M}} \cdot \frac{H}{\pi D} \\
& \alpha_{C}=\frac{C_{D}}{C_{M}} \cdot\left(1+\frac{{ }^{T U}}{\pi H}\right)^{2} \cdot \frac{H}{\pi D}
\end{aligned}
$$

Thus for large values of $\mathrm{N}_{\mathrm{K}}$ loading is drag dominated and for low values of $\mathrm{N}_{K}$ it $i:$ inertia dominated, and currents flowing approximately parallel to the wave direction increase the drag dominance. 


\section{APPENDIX II}

Assessment of the Significance of Errors in the Wave Force

Coefficient Values in Evaluating the Wave Force

A guide as to how the drag and inertia force components of Morison's equation vary with the ratio of drag coefficient, $C_{D}$, to inertia coefficient, $C_{M}$, and Keulegan-carpenter number, $N_{K}$, is given btlow. The variour tables presented are based on linear wave thcory and apply to circular cylinders and may be used to assess the significance of any errors in the wave force coefficient values in eveluating the wave force.

i) The relnt,ive inturitude of the drag force, $F_{D}$, to the, inertia force, at the instant, of the maximum wave force at n. proticular depth may be shown to be given by,

$$
\frac{F_{D}}{F_{I}}=4\left(\frac{C_{D}}{C_{M}}\right)^{2} \cdot \frac{N_{K}^{2}}{\pi^{\frac{4}{4}}}
$$

Table II.I below gives values of $\mathrm{F}_{D} / F_{I}$ as a function of the ratio, ${ }{ }_{1} / C_{M}$ and $N_{K}$.

TABLE: II.]

\begin{tabular}{|c|c|c|c|c|c|c|c|}
\hline${ }_{K}^{C} C_{M}$ & $1 / 5$ & $1 / I_{t}$ & $1 / 3$ & $1 / 2$ & $3 / 4$ & 1 & 2 \\
\hline 5 & 0.04 & 0.06 & 0.11 & 0.26 & 0.58 & 1.03 & 4.11 \\
\hline 11 & 0.20 & 0.31. & 0.55 & 1.24 & 2.79 & 4.97 & 19.87 \\
\hline 15 & 0.37 & 0.58 & 1.03 & 2.31 & 5.20 & 9.24 & 36.96 \\
\hline 20 & 0.66 & 1.03 & 1.83 & 4.11 & 9.214 & 16.43 & 65.70 \\
\hline 25 & 3.03 & 1.60 & 2.85 & 6.42 & 14.44 & 25.66 & 102.66 \\
\hline 1,0 & 2.63 & 4.11 & $7 \cdot 30$ & 16.43 & 36.96 & 65.70 & 262.81 \\
\hline 70 & 8.05 & $1 \because .58$ & 22.36 & $50 \cdot 30$ & $113: 18$ & 201.21 & 804.85 \\
\hline 100 & 16.1 .3 & 25.66 & 45.63 & 102.66 & 230.98 & 410.64 & 164.2 .56 \\
\hline
\end{tabular}


ii) The relative magnitude of the maximum drag force, $F_{D}$ max, to the maximum inertia force, $\mathrm{F}_{\mathrm{I}} \max$, occuring during a wave cycle at a particular depth, may be shown to be given by,

$$
\frac{F_{D \max }}{F_{I \max }}=\frac{C_{D}}{C_{M}} \cdot \frac{N_{K}}{\pi^{2}}
$$

Table II.2 below gives values of $\mathrm{F}_{\mathrm{D} \text { max }} / \mathrm{F}_{\mathrm{I} \text { max }}$ as a function of the ratio $\mathrm{C}_{\mathrm{D}} / \mathrm{C}_{\mathrm{M}}$ and $\mathrm{N}_{\mathrm{K}}$.

\section{TABLE II.?}

\begin{tabular}{|c|c|c|c|c|c|c|c|}
\hline & $1 / 5$ & $1 / 1 / 4$ & $1 / 3$ & $1 / 2$ & $3 / 4$ & 1 & 2 \\
\hline 5 & 0.10 & 0.13 & 0.17 & 0.25 & 0.38 & 0.51 & .1 .0 .7 \\
\hline 11 & 0.2 .2 & 0.283 & 0.37 & 0.56 & 0.84 & $1.1]$ & 2.23 \\
\hline 15 & 0.31 & (1. . \& & 0.52 & 0.75 & $.1 / 4$ & 1.52 & 3.04 \\
\hline 20 & $0.1+2$ & 0.51 & 0.68 & 1.01 & 1. .52 & 2.03 & 4.05 \\
\hline 25 & 0.51 & 0.63 & 0.84 & 1.27 & 1.90 & 2.53 & 5.07 \\
\hline 40 & 0.81 & 1.01 & 1.35 & 2.03 & 3.04 & 4.05 & 8.11 \\
\hline 70 & 1.42 & 1.77 & 2.36 & 3.55 & 5.32 & 7.09 & 14.18 \\
\hline 100 & 2.03 & 2.53 & 3.38 & 5.07 & 7.60 & 10.13 & 20.26 \\
\hline
\end{tabular}

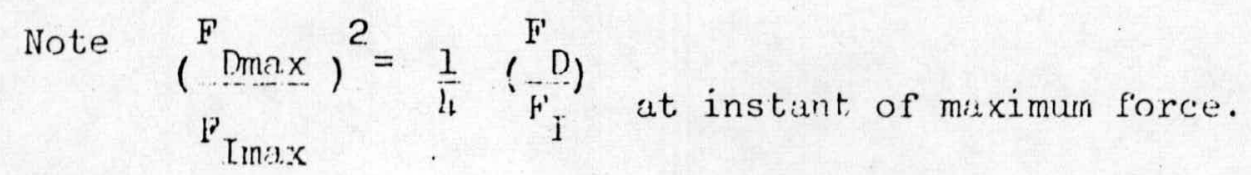

iii) The maximum allowable error in $C_{M}$ in drae doninant conditions for less than $10 \%$ relativi error in the maximum force at a particular depth, may be estimated as follows. 
Take the error in $C_{M}$ as $a$, such that $C_{M}=C_{M o}(1+a)$, then neglecting any error in $C_{D}$, the relative error in the non-dimensional force $F / \rho D^{3} \omega^{2}$, may be shown to be given by,

$$
\text { relative error }=\frac{\alpha(2+\alpha)}{\frac{4}{\pi^{4}\left(\frac{C_{D}}{C_{M_{0}}}\right)} \frac{N_{K}^{2}}{C^{2}}+1}
$$

Table II. 3 below gives the maximum values of $\alpha$, as a function of the ratio $C_{D} / C_{M}$ and $N_{K}$, such that the calculated maximum force will differ by less than $10 \%$ from the force calculated using $\mathrm{C}_{\mathrm{Mo}}$.

TABLE II.3

\begin{tabular}{|c|c|c|c|c|c|c|c|}
\hline$N_{K}^{C}\left(1 / C_{1}\right.$ & $1 / 5$ & $1 / 4$ & $1 / 3$ & $1 / 2$ & $3 / 4$ & 1 & 2 \\
\hline 5 & 0.05 & 0.05 & 0.05 & 0.06 & 0.08 & 0.10 & 0.23 \\
11 & 0.06 & 0.06 & 0.07 & 0.11 & 0.17 & 0.26 & 0.75 \\
15 & 0.07 & 0.08 & 0.10 & 0.15 & 0.27 & 0.42 & 1.19 \\
20 & 0.08 & 0.10 & 0.13 & 0.23 & 0.42 & 0.66 & 1.77 \\
25 & 0.10 & 0.12 & 0.17 & 0.32 & 0.60 & 0.91 & 2.37 \\
40 & 0.17 & 0.23 & 0.35 & 0.66 & 1.19 & 1.72 & 4.23 \\
70 & 0.38 & 0.54 & 0.81 & 1.47 & 2.52 & 3.61 & 8.03 \\
100 & 0.66 & 0.89 & 1.36 & 2.37 & 3.92 & 5.49 & 11.86 \\
\hline
\end{tabular}

For example, if $C_{D}=0.5$ is selected with an assumed $C_{M}=C_{M o}$ value of $1.5,\left(C_{D} / C_{M}=1 / 3\right)$ at $N_{K}=40$, then the $C_{M}$ value actually used could be up to $2.03(=1.5(1+0.35))$, without altering the relative error in the maximum force by more than $10 \%$

iv) The maximum allowable error in $C_{D}$ in inertia dominant conditions for less than $10 \%$ relative error in the maximum force at a particular depth, may be estimated as follows.

Take the error in $C_{D}$ as $B$, such that $C_{D}=C_{D o}(1+\beta)$, then neglecting any error in $C_{M}$, the relative error in the non-dimensional force $F / \rho D^{3} \omega^{2}$ miy be shown to be given by, 


$$
\text { relative error }=\frac{\beta+\gamma\left(\frac{1}{1+\beta}-1\right)}{1+\gamma}
$$

where $y=\frac{\pi^{4}}{4}{\underset{C}{C_{D O}}}_{\left(\stackrel{C^{2}}{2}\right)}^{N_{K}^{2}}$

Table II. 4 below gives the maximum values of $\beta$, as a function of the ratio $C_{D} / C_{M}$ and $N_{K}$, such that the calculated maximum force will differ by less than $10 \%$ from the force calculated using $C_{D o}$.

TABIE II. 4

\begin{tabular}{|c|c|c|c|c|c|c|c|}
\hline$N_{K}^{C} C_{M}$ & $1 / 5$ & $1 / 4$ & $1 / 3$ & $1 / 2$ & $3 / 4$ & 1 & 2 \\
\hline 3 & 73.60 & 16.8 & 25.98 & 3.1 .11 & 4.49 & 2.24 & 0.34 \\
5 & 25.98 & 16.35 & 8.85 & 3.52 & 1.22 & 0.54 & 0.16 \\
11 & 4.76 & 2.79 & 1.31 & 0.42 & 0.19 & 0.15 & 0.11 \\
15 & 2.214 & 1.23 & 0.54 & 0.22 & 0.14 & 0.12 & 0.10 \\
20 & 1.02 & 0.54 & 0.27 & 0.16 & 0.12 & 0.11 & 0.10 \\
25 & 0.53 & 0.31 & 0.19 & 0.13 & 0.11 & 0.11 & 0.10 \\
40 & 0.20 & 0.18 & 0.13 & 0.11 & 0.11 & 0.10 & 0.10 \\
\hline
\end{tabular}

For example, if $C_{M}=2.0$ is selected with an assumed $C_{D}=C_{D O}$ value of $1.0\left(C_{D} / C_{M}=1 / 2\right)$, at $N_{K}=11$, then the $C_{D}$ value used could be up to $1.42(=1.0(1+0.42))$ without altering the relative error in the maximum force by more than $10 \%$. 
TABLE 2.1 - Summary of Literature Giving Explicit $C_{M}$ and $C_{D}$ Values The $C_{M}$ and $C_{D}$ values given in this Table are applicable to the calculation of the horizontal component of wave force, and
$\mathrm{R}_{\text {and }} \mathrm{N}_{\mathrm{K}}$ have been evaluated using the maximum horizontal wave particle orbit velocity at the still water level, unless otherwise stated.

\begin{tabular}{|c|c|c|c|c|c|c|c|}
\hline futhor & Location & "Sea-State" & Structure & $\mathrm{R}_{\mathrm{e}}$ & $C_{D}$ & $\mathrm{C}_{\mathrm{M}}$ & Reliability/Wave Theory \\
\hline $\begin{array}{l}\text { iageard } \\
\text { ard Jean } \\
2 \operatorname{cong} \\
\text { Re:. } 2.1\end{array}$ & $\begin{array}{l}\text { Gulf of Mexico } \\
\text { Wave Force } \\
\text { Projects I \& II }\end{array}$ & $\begin{array}{l}\text { Hurricane storm } \\
\text { waves } \\
\qquad<\mathrm{H}<40 \mathrm{ft} . \\
6<\mathrm{T}<17 \mathrm{sec} . \\
\mathrm{d}=30 ; 100 \mathrm{ft} .\end{array}$ & $\begin{array}{l}\text { Vertical cylinders } \\
\quad \mathrm{d}=30 \mathrm{ft} . \\
\begin{array}{l}D=1,2,3,4 \mathrm{ft} . \\
\mathrm{d}=100 \mathrm{ft} . \\
D=3.7 \mathrm{ft} .\end{array}\end{array}$ & $\begin{array}{l}15-50 \quad 10^{4}-10^{7} \\
\text { Evaluated using Stokes } 5 \mathrm{th} \\
\text { order theory values beneath } \\
\text { the wave crest, considering } \\
\text { variation with depth. }\end{array}$ & $\begin{array}{l}1.2-0.5 \\
\text { Decreasing } \\
\text { w1th } R_{e} \cdot \\
\text { For in }\end{array}$ & $\begin{array}{l}1.33 \\
\text { nline force }\end{array}$ & $\begin{array}{l}\text { Calculated forces averaged over H, T, d } \\
\text { agreed to within loo of measured total forces, } \\
\text { Calculated and measured local force max } \\
\text { agreed to within } 50 \% \text {. Effeets of currents } \\
\text { were not considered. Stream furction wa. } \\
\text { theory is to be used with wave force } \\
\text { evaluation techinique g-ven. }\end{array}$ \\
\hline $\begin{array}{l}\text { Ere:schneider } \\
\text { 29ó? } \\
\text { Ref. } 2.2\end{array}$ & $\begin{array}{l}\text { Californian } \\
\text { coast, } \\
\text { Davenport. }\end{array}$ & $\begin{array}{l}\text { Storm waves } \\
5<H<20 \mathrm{ft} . \\
9<\mathrm{T}<17 \mathrm{sec} . \\
45<\mathrm{d}<50 \mathrm{ft} .\end{array}$ & $\begin{array}{c}\text { Vertical cylinders } \\
D=+, 2 \mathrm{ft} .\end{array}$ & \begin{tabular}{l|c|}
$8-40$ & $10^{5}-10^{6}$ \\
Evaluated using linear theory \\
values beneath the wave crest, \\
cons1dering variation with depth.
\end{tabular} & $\begin{array}{l}0.4-1.5 \\
\text { H1gher } \\
\text { values } \\
\text { more } \\
\text { probable. }\end{array}$ & $\begin{array}{l}\quad 2-5 \\
\text { Lower } \\
\text { values } \\
\text { more } \\
\text { probable. }\end{array}$ & 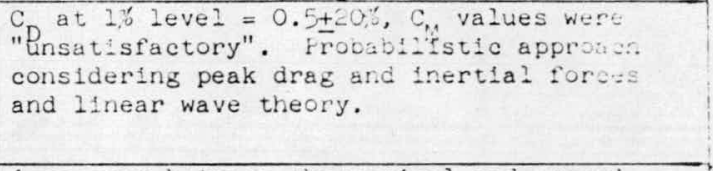 \\
\hline $\begin{array}{l}\text { Chskrabarti } \\
\text { sed Tam } \\
29=3 \\
\text { Ret. } 2.3\end{array}$ & Laboratory & $\begin{array}{c}\text { Linear sinusoidal } \\
\text { waves } \\
\begin{aligned} & 3<\mathrm{H}<10 \mathrm{in} . \\
& 1.0<\mathrm{T}<3.5 \mathrm{sec} . \\
& \mathrm{d}=47.25 \mathrm{in} .\end{aligned}\end{array}$ & $\begin{array}{l}\text { Vertical cylinder } \\
\qquad D=81 \text { in. }\end{array}$ & $10^{5}-10^{6}$ & $\begin{array}{l}\text { Drag } \\
\text { negligible }\end{array}$ & for $\frac{2.0}{\lambda} \simeq 0.2$ & $\begin{array}{l}\text { Agreement between theoretical and exper:- } \\
\text { mentally measured forces was excelien:. iave } \\
\text { forces were evaluated by diffraction } \\
\text { analysis, using linear wave theory. }\end{array}$ \\
\hline $\begin{array}{l}\text { Crskrabart: } \\
\text { nam and } \\
\text { Nozbert } \\
1995 \\
\text { Re: 2.4 }\end{array}$ & Laboratory & 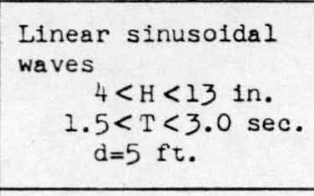 & $\begin{array}{l}\text { Cylinders held at } \\
\text { various inclinations } \\
\text { inline with and } \\
\text { normal to the waves } \\
D=3,5,7.5 \text { in. }\end{array}$ & \begin{tabular}{|c|c|}
$0-20$ & $5 \times 10^{3}-5 \times 10^{5}$ \\
Calculated using maximum \\
horizontal velocity averaged \\
over the length of the cylinder
\end{tabular} & $0-2.5$ & $1.0-2.5$ & $\begin{array}{l}\text { Large scatter in } C_{M} \text { and } C_{P} \text { values. Norison } \\
\text { equation used in } 3 \text {-dimens?ona vector : } \\
\text { with veloctin component norma to the } \\
\text { of the cyllinder. Measured and calculated } \\
\text { mean forces agreed to within lo\% usine } \\
\text { and } C_{D} \text { values for individual waves. }\end{array}$ \\
\hline 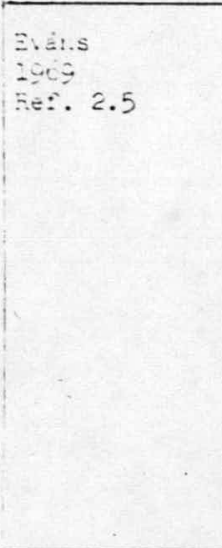 & $\begin{array}{l}\text { Julf of Mexico } \\
\text { Wave Force } \\
\text { Projects I \& II }\end{array}$ & $\begin{array}{c}\text { Project } I \\
10<\mathrm{H}<20 \mathrm{ft} . \\
6<\mathrm{T}<10 \mathrm{sec} . \\
\mathrm{d}=30 \mathrm{ft} . \\
\text { Project } \mathrm{II} \\
25<\mathrm{H}<45 \mathrm{ft} . \\
10<\mathrm{T}<17 \mathrm{sec} . \\
\mathrm{d}=100 \mathrm{ft} .\end{array}$ & $\begin{array}{l}\text { Vertical cylinders } \\
\qquad=1,2,3,4 \mathrm{ft} . \\
\text { Vertical cylinder } \\
D=3.7 . \mathrm{ft} .\end{array}$ & $\begin{array}{l}20-50 \quad 10^{5}-2 \times 10^{6} \\
\text { Evaluated using Stokes } 5 \text { th } \\
\text { order theory wave crest and } \\
\text { trough values. } \\
10-80 \\
\text { Evaluated using Stokes } 5 \text { th } \\
\text { order theory values beneath the } \\
\text { wave crest, considering } \\
\text { variation. With depth. }\end{array}$ & $\begin{array}{l}0.58 \\
\text { Standard } \\
0.33\end{array}$ & $\begin{array}{l}1.76 \\
\text { deviation } \\
1.06\end{array}$ & 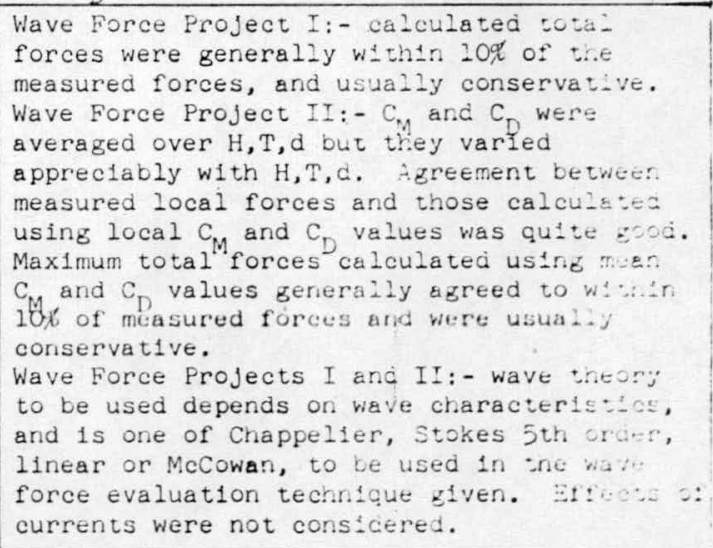 \\
\hline
\end{tabular}




\section{TABLE 2.1 (CONTD.)}

\begin{tabular}{|c|c|c|c|c|c|c|c|c|}
\hline Author & Location & "Sea-State" & Structure & $\mathrm{N}_{\mathrm{K}}$ & $\mathrm{R}_{\mathrm{e}}$ & $C_{D}$ & $\mathrm{C}_{\mathrm{M}}$ & Reliabllity/Wave Theory \\
\hline $\begin{array}{l}\text { 3serison } \\
=:=2 \\
207 \\
\text { Ae: } 2.6\end{array}$ & $\begin{array}{l}\text { Laboratory } \\
\text { model scale } \\
2: 120\end{array}$ & $\begin{array}{l}\text { Linear sinusoidal } \\
\text { waves simulating } \\
\text { full scale } \\
\text { conditions of } \\
\quad 21<\mathrm{H}<29 \mathrm{~m} \\
14<\mathrm{T}<17 \mathrm{sec} . \\
\mathrm{d}=120 \mathrm{~m}\end{array}$ & $\begin{array}{l}\text { Model of "condeep" } \\
\text { oll production } \\
\text { platform structure. } \\
\quad D=12 \mathrm{~m} \\
\text { for towers at water } \\
\text { line. }\end{array}$ & $0-5$ & $\begin{array}{l}3 \times 10^{7}-9 \times 10^{7} \\
\text { ful1 scale } \\
2.3 \times 10^{4}-6.9 \times 10^{4} \\
\text { model scale. }\end{array}$ & $\begin{array}{l}1.0 \\
\text { Assumed }\end{array}$ & $\begin{array}{r}2.0 \\
\text { values }\end{array}$ & $\begin{array}{l}\text { Agreement between calculated and meastred } \\
\text { forces and moments on the model was } \\
\text { excellent. Diffraction analyels lisin } \\
\text { linear wave theory was applled to the lar } \\
\text { base to obtan the velocity fleld for } \\
\text { platform supporting towers. The drag foree } \\
\text { was very small. }\end{array}$ \\
\hline $\begin{array}{l}\text { Jrace } \\
\text { arda } \\
\text { 2asciano } \\
\text { 2009 } \\
\text { Set. } 2.7\end{array}$ & $\begin{array}{l}\text { Hawai1 } \\
\text { coost }\end{array}$ & $\begin{array}{l}\text { Small sea waves } \\
1.7<H<5.6 \mathrm{ft} . \\
12<\mathrm{T}<16 \text { sec. } \\
\mathrm{d}=25 \mathrm{ft} .\end{array}$ & $\begin{array}{c}\text { Sphere on sea bed } \\
D=8 \mathrm{in} .\end{array}$ & $\begin{array}{l}\quad 8-60 \\
\text { Evaluated using } \\
\text { theory maximum } \\
\text { at the centre o }\end{array}$ & $\begin{array}{l}6 \times 10^{4}-3 \times 10^{5} \\
\text { Stokes } 3 \text { rd order } \\
\text { orbit velocity } \\
\text { of the sphere. }\end{array}$ & 0.7 & 1.2 & $\begin{array}{l}\text { Peak forces calculated using Stokes 3rd } \\
\text { order wave theory were generally withir. } \\
\text { of the measured forces. The wave force } \\
\text { drag dominant; a constant value of } C_{c h} \\
\text { assumed. The same } H, T \text {, for different } \\
\text { gave } C_{D} \text { values differing by over loct. }\end{array}$ \\
\hline 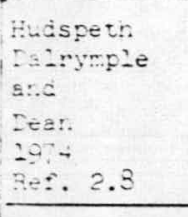 & $\begin{array}{l}\text { Gulf of Mexico } \\
\text { Wave Force } \\
\text { Projects I \& II }\end{array}$ & $\begin{array}{l}\text { Hurricane storm } \\
\text { waves } \\
\qquad \begin{array}{l}10<\mathrm{H}<40 \mathrm{ft} . \\
6<\mathrm{T}<17 \mathrm{sec} . \\
\mathrm{d}=33 \mathrm{ft} ., 100 \mathrm{ft} .\end{array}\end{array}$ & 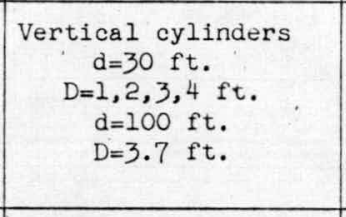 & $\begin{array}{l}10-70 \\
\text { Evaluated using } \\
\text { theory values b } \\
\text { crest, cons1der } \\
\text { with depth. }\end{array}$ & $\begin{array}{l}10^{4}-10^{7} \\
\text { Stokes } 5 \text { th order } \\
\text { veneath the wave } \\
\text { ing variation }\end{array}$ & $\begin{array}{l}1.2-0.5 \\
\text { Decreasing } \\
\text { w1th } R_{e}\end{array}$ & 1.1 & $\begin{array}{l}\text { Methods and results of data analysis usins } \\
\text { linear spectral wave theory and stream. } \\
\text { function wave theory were compared. "The } \\
\text { standard deviation between measured and } \\
\text { calculated forces was smallest for the c, ar. } \\
\text { C values given using the stream funcelch. } \\
\text { theory. }\end{array}$ \\
\hline $\begin{array}{l}\mathrm{Ben} \\
\mathrm{Be}=2.9\end{array}$ & Laboratory & \begin{tabular}{|c|} 
Regular and \\
irregular small waves \\
$0.068<\mathrm{H}<0.345 \mathrm{ft}$. \\
$0.9<\mathrm{T}<2.0 \mathrm{sec}$ \\
$\mathrm{d}=3 \mathrm{ft}$.
\end{tabular} & $\begin{array}{l}\text { Vertical cylinder } \\
D=6 \text { in. }\end{array}$ & $\begin{array}{l}0.4-2.2 \\
\text { Evaluated using } \\
\text { deep water appr }\end{array}$ & $\begin{array}{l}5.6 \times 10^{3}-2.5 \times 10^{4} \\
\text { Alry theory } \\
\text { coximation. }\end{array}$ & $\begin{array}{l}\text { Drag } \\
\text { negligible }\end{array}$ & 2.0 & $\begin{array}{l}\text { Linearised force rms values were in good. } \\
\text { agreement with the measured values, } \\
\text { justifying the neglect of drag. Spectral } \\
\text { analysis of two irregular waves also gave } \\
\text { CM }^{2}=2.0 \text {. }\end{array}$ \\
\hline $\begin{array}{l}\text { Jehnson } \\
2.3 \\
\text { RE: } 2.20\end{array}$ & Laboratory & \begin{tabular}{|} 
Linear sinusoidal \\
waves \\
$11.7<\mathrm{d} / \mathrm{H}<65.6$ \\
$0.4<\mathrm{d} / \lambda<2.5$
\end{tabular} & $\begin{array}{l}\text { Vertical cylinders } \\
D=0.25,0.50,0.67 \mathrm{ft} \text {. } \\
\text { top } 3 \mathrm{ft} \text {. below still } \\
\text { water level. }\end{array}$ & $1-12$ & $3.5 \times 10^{4}-1.6 \times 10^{5}$ & $\begin{array}{l}\text { Drag } \\
\text { negligible }\end{array}$ & 2.0 & $\begin{array}{l}\text { The measured forces acreed to within aC: } \\
\text { of the forces calculated using linear wave } \\
\text { theory. A theoretical formula for the wave } \\
\text { force was derived assuming drag was } \\
\text { negligible and } a_{M}=2.0 \text {. }\end{array}$ \\
\hline $\begin{array}{l}\text { Keulegan } \\
\text { and } \\
\text { =rpenter } \\
2: 50 \\
\text { Ser. } 2.11\end{array}$ & Laboratcry & $\begin{array}{l}\text { Linear sinusoidal } \\
\text { standing wave. } \\
0.10<\mathrm{U}_{\mathrm{m}}<0.75 \mathrm{~m} / \mathrm{sec} . \\
U_{\mathrm{m}}=\text { amplitude of } \\
\text { horizontal velocity. }\end{array}$ & $\begin{array}{l}\text { Horizontal cylinders } \\
\text { and flat plates sub- } \\
\text { merged under standing } \\
\text { wave node. } \\
0.5<D<3.0 \text { in. }\end{array}$ & $\mid \begin{array}{l}2-120 \\
\text { Evaluated from } \\
\text { given. }\end{array}$ & $\begin{array}{l}4 \times 10^{3}-3 \times 10^{4} \\
\text { values of } U_{m}\end{array}$ & 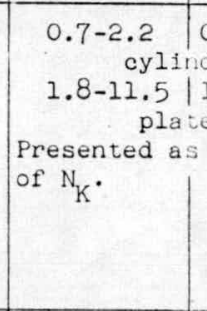 & $\begin{array}{l}0.6-2.6 \\
\text { nders } \\
\text { |1.1-5.0 } \\
\text { tes } \\
\text { s functions } \\
\text { i }\end{array}$ & 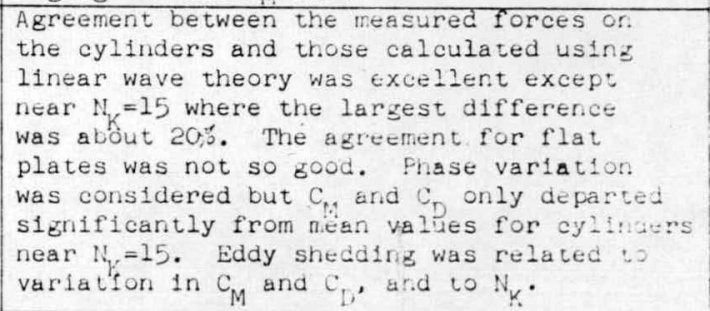 \\
\hline 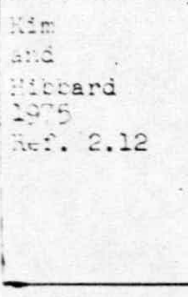 & $\begin{array}{l}\text { Sass Straits } \\
\text { iustralia }\end{array}$ & $\begin{array}{l}\text { Small amplitude } \\
\text { sea waves. } \\
2.55<\mathrm{H}<9.87 \mathrm{ft} \text {. } \\
\text { (significani helght) } \\
4.35<\mathrm{T}<8.70 \text { sec. } \\
\text { (dominant period) } \\
\mathrm{d}=7.25 \mathrm{ft} \text {. } \\
\text { at test } \mathrm{section} \text {. } \\
\text { current }=1 \mathrm{ft} / \mathrm{sec} \text {. }\end{array}$ & $\begin{array}{l}\text { Vertical cylinder } \\
\mathrm{D}=12.75 \text { in. }\end{array}$ & $\begin{array}{l}12-80 \\
\text { Evaluated using } \\
\text { velocity at tes }\end{array}$ & $\begin{array}{l}2.5 \times 10^{5}-8.0 \times 10^{5} \\
\text { measured } \\
\text { t section. }\end{array}$ & $\begin{array}{l}0.61 \\
\text { Standard } \\
0.24\end{array}$ & $\begin{array}{c}1.2 \\
\text { deviation } \\
0.22\end{array}$ & 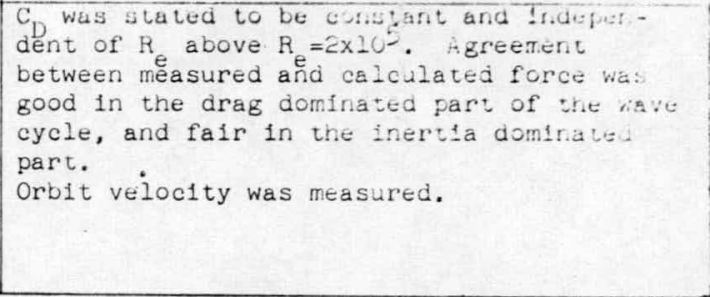 \\
\hline
\end{tabular}


TABLE 2.1 (CONTD.)

\begin{tabular}{|c|c|c|c|c|c|c|c|c|}
\hline - lithor & Location & "Sea-State" & Structure & $\mathrm{N}_{\mathrm{K}}$ & $\mathrm{R}_{\mathrm{e}}$ & $C_{D}$ & $\mathrm{C}_{\mathrm{M}}$ & Rellabll1ty/Wave Theory \\
\hline $\begin{array}{l}\text { Yercier } \\
2: 3 \\
\text { Set. } 2.13\end{array}$ & Laboratory & $\begin{array}{l}\text { Low speed constant } \\
\text { stream } \\
\qquad d=10 \text { in. }\end{array}$ & $\begin{array}{l}\text { Vertical cylinder } \\
\text { oscillated parallel } \\
\text { and transverse to } \\
\text { stream } \\
\qquad D=0.5,1.0 \mathrm{in} .\end{array}$ & Not cons1dered & $\begin{array}{l}6 \times 10^{3}-1.3 \times 10^{4} \\
\text { Stream velocity } \\
\text { value (U ). } \\
\text { Interaction } \\
\text { with osclilation } \\
\text { not considered. }\end{array}$ & $\mid \begin{array}{c}1.0-2.5 \\
\text { Transverse } \\
1.0-5.0 \\
\text { Parallel osc }\end{array}$ & $\begin{array}{l}0-1.5 \\
\text { oscillations } \\
\mid \begin{array}{l}\mathrm{v} \\
0.2-0.8 \\
\text { scillations }\end{array} \\
\end{array}$ & $\begin{array}{l}C_{M} \text { and } C_{D} \text { were found to depend on the } \\
\text { velocity and direction of the stream and } \\
\text { the amplitude of oscillation. Drag force } \\
\text { correlated with } \frac{f D}{U_{O}} \text { ( } f=\text { frequency). A wave } \\
\text { theory was not used. }\end{array}$ \\
\hline $\begin{array}{l}\text { Yortson } \\
\text { O'Erien } \\
\text { Oonson } \\
\text { and } \\
\text { Scraaf } \\
2950 \\
\text { Be:. } 2.14 \\
\end{array}$ & Laboratory & $\begin{array}{l}\text { Linear sinusoidal } \\
\text { waves } \\
0.1<\mathrm{d} / \mathrm{A}<0.5 \\
4.8<\mathrm{d} / \mathrm{H}<18.2\end{array}$ & $\begin{array}{c}\text { Vert1cal cylinder } \\
0.01<D / \lambda<0.04 \\
0.2<D / H<0.8\end{array}$ & $4-25$ & $2 \times 10^{3}-10^{4}$ & $1.626 \pm 0.4141$ & $1.508 \pm 0.197 \mid \begin{array}{l}\mathrm{M} \\
\mathrm{u} \\
\mathrm{a} \\
\mathrm{a} \\
\mathrm{d} \\
\mathrm{R}\end{array}$ & 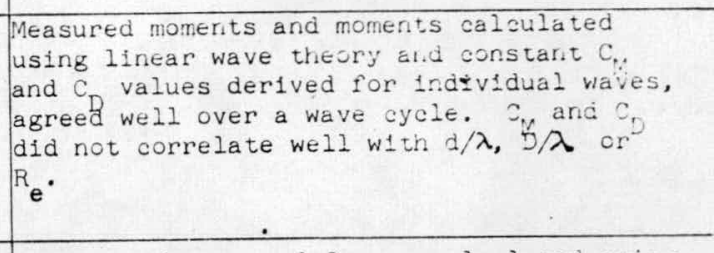 \\
\hline $\begin{array}{l}\text { O'brien } \\
\text { snd } \\
\because \text { ortson } \\
2952 \\
\text { Re: } 2.15\end{array}$ & Laboratory & $\begin{array}{l}\text { Linear sinusoidal } \\
\text { waves } \\
0.2<\mathrm{H}<0.4 \mathrm{ft} . \\
0.6<\mathrm{T}<2.2 \mathrm{sec} \\
0.9<\mathrm{d}<1.3 \mathrm{ft} .\end{array}$ & $\begin{array}{l}\text { Spheres on bottom } \\
\text { of water channel. } \\
0.030<D<0.125 \mathrm{ft} \text {. }\end{array}$ & $\begin{array}{l}1-14 \\
\text { Evaluated using } \\
\text { velocity at cen }\end{array}$ & $\begin{array}{l}1.9 \times 10^{3}-7.8 \times 10^{3} \\
\text { maximum orbital } \\
\text { entre of sphere. }\end{array}$ & $0.8-3.0$ & $0.9-1.6$ & $\begin{array}{l}\text { Measured forces and forces calculated usine } \\
\text { linear wave theory and constant } C_{y} \text { and } C_{\text {, }} \\
\text { values derived for indivicual waves, agred } \\
\text { well over a wave cycle. Alternative } \\
\text { derivation methods gave C, values varyine } \\
\text { over loo; for the same wave and C value. }\end{array}$ \\
\hline $\begin{array}{l}\text { Easpe, and } \\
\text { Ereusers } \\
290^{7} \\
\text { Sef. } 2.16\end{array}$ & Laboratory & $\begin{array}{c}\text { (a) Structure } \\
\text { oscillated in still } \\
\text { water. } \\
0.5<\mathrm{T}<3.0 \mathrm{sec} \\
\text { semi-amplitude } \\
0.01-0.20 \mathrm{~m} \\
\text { (b) Linear } \\
\text { sinusoidal waves. } \\
0.43<\mathrm{T}<0.80 \mathrm{sec} \\
0.007<\mathrm{H}<0.075 \mathrm{~m} \\
\mathrm{~d}=0.300,0.406 \\
0.555,0.775 \mathrm{~m} \\
\end{array}$ & $\begin{array}{l}\text { (a) Horizontal } \\
\text { cylinder and plate } \\
D=0.075 \mathrm{~m} \\
\text { (b) Vertical square } \\
\text { piles. } \\
D=0.025,0.046,0.063 \mathrm{~m}\end{array}$ & $\begin{array}{l}\text { (a) } 0.8-16.7 \\
\text { Evaluated us } \\
\text { amplitude } \\
\text { (b) } 1-10\end{array}$ & $\begin{array}{l}7.7 \times 10^{3}-2.7 \times 10^{4} \\
\text { using the } \\
\text { of osc1litiotion } \\
10^{3}-1.6 \times 10^{4}\end{array}$ & $\begin{array}{r}\text { (a) } 0.5-2.9 \\
\text { cyli } \\
3-13 \text { | } \\
\text { pla } \\
\text { Presented as } \\
\text { of N N. } \\
\text { (b) Not cons }\end{array}$ & $\begin{array}{l}\text { dinder } \\
\text { ling-2.5 } \\
\text { late functions } \\
\text { as fidered. }\end{array}$ & 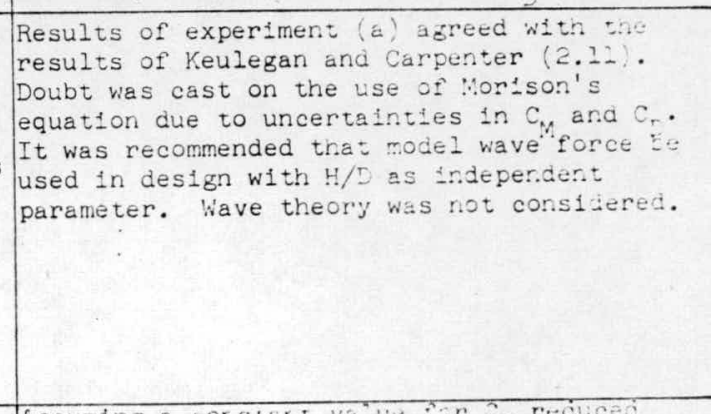 \\
\hline $\begin{array}{l}\text { Esnce } \\
2909 \\
\text { Re:- } 2.17\end{array}$ & Laboratory & $\begin{array}{l}\text { Pulsating water } \\
\text { tunnel }\end{array}$ & $\begin{array}{l}\text { Vertical cylinders } \\
0.025<D<0.3 \mathrm{~m}\end{array}$ & $\begin{array}{l}\text { 9-230 } \\
\text { from a/D values } \\
\text { quoted. }\end{array}$ & $\begin{array}{l}\quad 4 \times 10^{3}-7 \times 10^{5} \\
\text { Instantaneous } \\
\text { values at } \\
\text { max1mum force. }\end{array}$ & $\begin{array}{l}0.4-7.0 \\
\text { As a } \\
\text { function of } \\
\text { a/D and } R_{e} \\
0.4-1.7 \\
\text { for } \mathrm{N}_{\mathrm{K}}>0\end{array}$ & 2.0 & 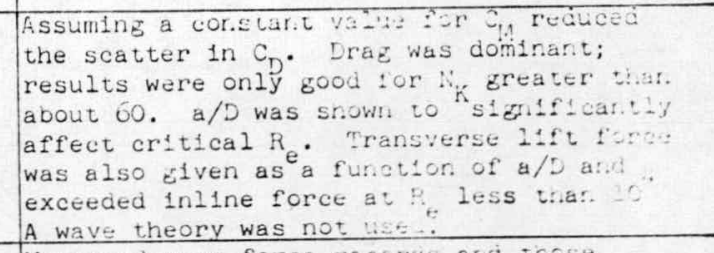 \\
\hline $\begin{array}{l}\text { Re:d } \\
29 x \\
\text { Re:. } 2.18\end{array}$ & Gulf of Sexico & $\begin{array}{l}\text { Small amplitude } \\
\text { sea waves. } \\
\quad 2<\mathrm{H}<4 \mathrm{ft} \text {. } \\
3<\mathrm{T}<5 \mathrm{sec} \text {. } \\
\text { wind speed } 10-30 \mathrm{mph} \\
\text { current } 0.5-0.7 \mathrm{ft} / \\
\text { sec. at surface. }\end{array}$ & $\begin{array}{l}\text { Vertical cylinder } \\
\text { clamped above water } \\
\text { with other end loose. } \\
\text { D=8.625 in. }\end{array}$ & $10-20$ & $10^{5}-2 \times 10^{5}$ & $\begin{array}{l}\quad 0.53 \\
\text { Standard dev } \\
=0.20\end{array}$ & $\begin{aligned} & 1.47 \\
\text { eviation } & =0.36\end{aligned}$ & 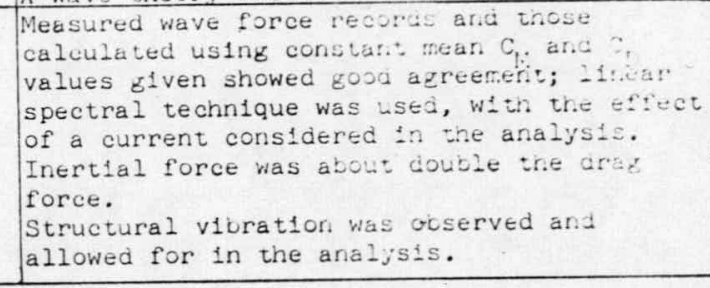 \\
\hline
\end{tabular}


TABLE 2.1 (CONTD.)

\begin{tabular}{|c|c|c|c|c|c|c|c|}
\hline Author & Location & "Sea-State" & Structure & $\mathrm{N}_{\mathrm{K}}$ & ${ }^{C}{ }_{D}$ & $\mathrm{C}_{\mathrm{M}}$ & Reliability/Nave Theory \\
\hline 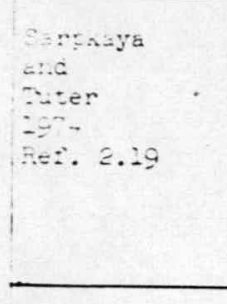 & Iaboratory & $\begin{array}{l}\text { l-dimensional simple } \\
\text { harmonic flow. } \\
\text { amplitude }=11 \text { in. } \\
\mathrm{T}=2.86 \mathrm{sec} \text {. } \\
\mathrm{d}=20 \mathrm{in} .\end{array}$ & \begin{tabular}{|l|} 
Horizontal cylinders \\
extended across the \\
horizontal limb of \\
a U-tube \\
$1.0<D<2.5$ in. \\
Spheres hung on wires \\
in the horizontal \\
limb of a U-tube. \\
$1.125<D<3.975$ in.
\end{tabular} & $\begin{array}{l}0-50 \\
\text { Evaluated using the amplitude } \\
\text { of the simple harmonic flow } \\
\end{array}$ & $\begin{array}{l}0.0-2.1 \\
0.0-0.8 \text { sphe } \\
\text { Presented as } \\
\text { of } \mathrm{N}_{\mathrm{K}} \text {. }\end{array}$ & $\begin{array}{l}\text { inder } \\
0.8-2.1 \\
\text { here } \\
1.0-1.5 \\
\text { functions }\end{array}$ & $\begin{array}{l}\text { Lift forces up to } 1.5 \text { times drag force wer: } \\
\text { measured up to } \mathrm{N} \text { values of about } 20 \text {. } \\
\text { Measured and calculated forces agreed to } \\
\text { within } 15 ; \text {; the difference was largest at } \\
\mathrm{N}_{K}=12 \text { for cyllnders and between M } \\
\text { ahd } 22 \text { for spheres. Generally agteement } \\
\text { was excellent. }\end{array}$ \\
\hline $\begin{array}{l}\text { Sarpkaya } \\
290 \\
\text { Set. } 2.20\end{array}$ & $\begin{array}{c}\text { Laboratory } \\
\end{array}$ & $\begin{array}{l}\text { l-dimensional } \\
\text { simple harmonic flow } \\
\mathrm{T}=5.272 \text { sec. }\end{array}$ & \begin{tabular}{|l|} 
Smooth and rough \\
horizontal cylinders \\
extended across the \\
horizontal limb of \\
a U-tube, larger \\
than that used in \\
reference 2.99 \\
$2.0<D<6.5$ in. \\
$0.001<\frac{k_{r}}{D}<0.02$
\end{tabular} & 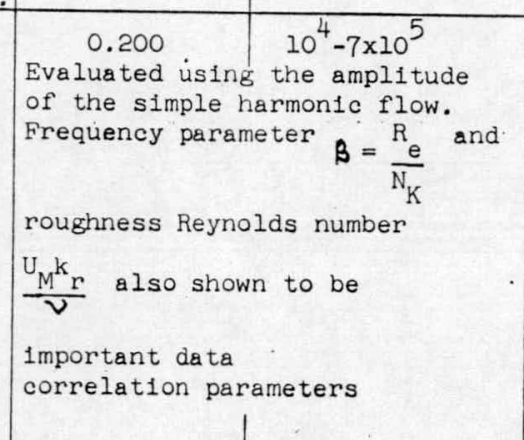 & $\mid \begin{array}{c}0.5-2.0 \\
\text { Presented as } \\
\text { of } R_{e}, N_{K} \text { an }\end{array}$ & $\begin{array}{l}0.7-1.9 \\
\text { functions } \\
\text { ad } \frac{k_{r}}{D}\end{array}$ & $\begin{array}{l}\text { Very little data scatter; lift coefficien: } \\
\text { and Strouhal number also found to be } \\
\text { functions of } \mathrm{R}_{e} \text {. N } \mathrm{N}_{K} \text { and } \mathrm{k} / \mathrm{D} \text {. Lift forces } \\
\text { can be large and must be considered in } \\
\text { design; Strouhal number varled betwen } \\
0.15 \text { and } 0.45 \text {. Agreement between measurec } \\
\text { and calculated forces was excellent excep: } \\
\text { between } N_{K} \text { values of about } 10 \text { and } 20 \text {. These } \\
\text { discrepancies were largely attributed to eday } \\
\text { shedding associated with large lift forces } \\
\text { and shedding of single vortices. }\end{array}$ \\
\hline $\begin{array}{l}\text { Sekt:a } \\
29 ? 5 \\
\text { Bef. } 2.22\end{array}$ & Laboratory & $\begin{array}{c}\text { Small amplitude } \\
\text { regular waves. } \\
5<\mathrm{H}<42 \mathrm{~cm} \\
0.9<\mathrm{T}<5.0 \mathrm{sec} . \\
0.005<\mathrm{H} / \lambda<0.1 \\
\mathrm{~d}=133 \mathrm{~cm}\end{array}$ & $\begin{array}{l}1 / 60 \text { scale model of } \\
\text { jacket structure with } \\
\text { cross framing, with } \\
15 \text { conductor tubes } \\
\text { and with no conductor } \\
\text { tubes, at various } \\
\text { incidences to the } \\
\text { flow. }\end{array}$ & $\begin{array}{l}\text { 10-100 } 10^{3}-3 \times 10^{4} \\
\text { Evaluated using maximum } \\
\text { velocity at still water level } \\
\text { as given by Stokes } 5 \text { th order } \\
\text { theory, and the dameter of } \\
\text { the maln column. }\end{array}$ & $\begin{array}{l}0.6 \\
\text { Representat } \\
\text { whole struc } \\
\text { values smal. } \\
\text { conductor ti } \\
\text { included. }\end{array}$ & $\begin{array}{l}1.6 \\
\text { tive of } \\
\text { cture; } \\
\text { ller when } \\
\text { tubes }\end{array}$ & $\begin{array}{l}C_{M} \text { and } C_{D} \text { showed a markedly different } \\
\text { correlation with N } \text { to that obtained by } \\
\text { Keulegan and Carpenter (2.11). Morison's } \\
\text { equation was used 1n } 3 \text {-dimensional vector } \\
\text { form with velocity component normal to the } \\
\text { axis of the cylinder. } \\
\text { Current drag was considered separately. } \\
\text { Application of model results to prototype } \\
\text { is uncertain. }\end{array}$ \\
\hline $\begin{array}{l}\text { Sinark } \\
\text { snd } \\
\text { Herbion } \\
2900 \\
0 ., 2,22 \\
\end{array}$ & Laboratory & $\begin{array}{l}\text { Linear sinusoidal } \\
\text { waves } \\
1.5<\lambda / \mathrm{d}<6.0 \\
0.01<\mathrm{H} / \lambda<0.11 \\
\mathrm{~d}=13,18,24 \mathrm{nn} .\end{array}$ & $\begin{array}{l}\text { Rectangular and } \\
\text { semi-cylindrical } \\
\text { model "011 storage } \\
\text { tanks" } \\
\text { D=8 in. }\end{array}$ & \begin{tabular}{|c|c|}
$0-11$ & $2 \times 10^{3}-2.6 \times 10^{6}$ \\
Evaluated using maximum orb1t \\
veloc1ty at centre of object.
\end{tabular} & $\begin{array}{l}\text { Drag } \\
\text { negligible }\end{array}$ & $\begin{array}{l}1.2-2.2 \\
\text { Optimum } \\
\text { value }=1.8\end{array}$ & $\begin{array}{l}\text { Agreement between measured forces and } \\
\text { forces calculated using linear wave theory } \\
\text { was good. Force 1ncreased with } H / \lambda \text { and } \\
\lambda / d \text {, but } C_{M} \text { was independent of these } \\
\text { parameters. }\end{array}$ \\
\hline 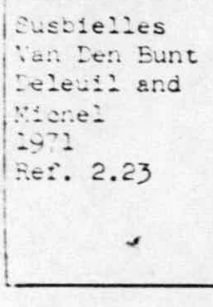 & $\begin{array}{l}\text { Laboratory } \\
\text { scaled } 1: 30 \text { or. } \\
\text { Froude's scale } \\
\text { law }\end{array}$ & $\begin{array}{l}\text { Linear sinusoidal } \\
\text { and irregular } \\
\text { waves } \\
2<\mathrm{H}<16 \mathrm{~m} \\
6<\mathrm{T}<18 \mathrm{sec} . \\
\mathrm{d}=20 \mathrm{~m} \\
\text { full scale values }\end{array}$ & $\begin{array}{l}\text { Vertical cylinder } \\
D=1 \mathrm{~m} \\
\text { full scale }\end{array}$ & $\begin{array}{l}9.2 \times 10^{5}-5.0 \times 10^{6} \\
\text { ful1 scale } \\
5.6 \times 10^{3}-3.0 \times 10^{4} \\
\text { model scale }\end{array}$ & $\begin{array}{l}0.6-3.0 \\
\text { Values in ir } \\
\text { waves consic } \\
\text { be higher. }\end{array}$ & $\begin{array}{l}0.8-2.1 \\
\text { irregular } \\
\text { idered to }\end{array}$ & 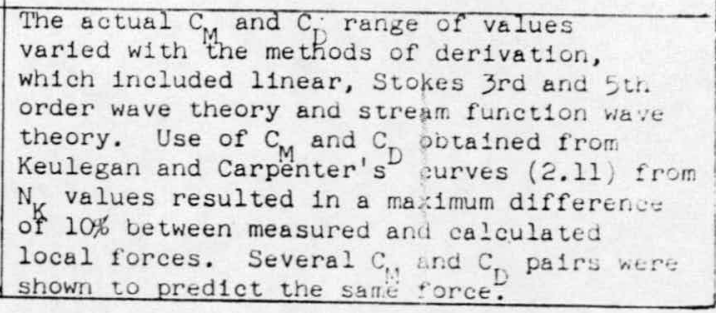 \\
\hline
\end{tabular}


AABIE 2.1 (CONTD.)

\begin{tabular}{|c|c|c|c|c|c|c|c|c|}
\hline Author & Location & "Sea-State" & Structure & $\mathrm{N}_{\mathrm{K}}$ & $\mathrm{R}_{\mathrm{e}}$ & $C_{D}$ & $C_{M}$ & Reliab1l1ty/Wave Theory \\
\hline $\begin{array}{l}\text { Whetler } \\
\text { 2909 } \\
\text { Re:. } 2.24\end{array}$ & $\begin{array}{l}\text { Gulf of Mexico } \\
\text { Wave Force } \\
\text { Project II }\end{array}$ & $\begin{array}{c}\text { Hurricane storm } \\
\text { waves } \\
20<H<40 \mathrm{ft} . \\
10<\mathrm{T}<17 \text { sec. } \\
d=99 \mathrm{ft} .\end{array}$ & $\begin{array}{l}\text { Vertical cylinder } \\
\qquad=3.7 \mathrm{ft} .\end{array}$ & $24-65$ & $2.5 \times 10^{6}-5.0 \times 10^{6}$ & $\begin{array}{l}0.6 \\
\text { Smaller } \\
0.4 \text {, at } \\
\text { surface }\end{array}$ & $\begin{array}{l}1.2-2.0 \\
\text { Varying } \\
\text { w1th } \\
\text { depth }\end{array}$ & $\begin{array}{l}\text { Measured and calculated maximum local } \\
\text { forces differed by up to } 40 \% \text { in hlgh waves. } \\
\text { A linear spectral method of däta analysts } \\
\text { was used. Effect of currents was not } \\
\text { considered. }\end{array}$ \\
\hline 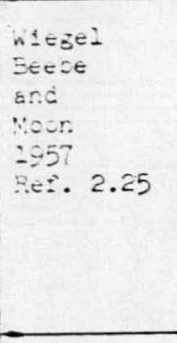 & $\begin{array}{l}\text { Pacific coast } \\
\text { of California } \\
\text { at Davenport. }\end{array}$ & $\begin{array}{l}\text { Storm waves } \\
5<H<20 \mathrm{ft} \text {. } \\
9<\mathrm{T}<17 \mathrm{sec} . \\
45<\mathrm{d}<50 \mathrm{ft} \text {. } \\
\text { wind waves super- } \\
\text { 1mposed on the } \\
\text { swell. }\end{array}$ & $\begin{array}{l}\text { Vertical cylinders } \\
D=6.625 \text { in. } \\
1.0,2.0,5.0 \mathrm{ft} . \\
\text { w1th test section } \\
\text { at various depths. }\end{array}$ & $\begin{array}{l}8-40 \\
\text { Evaluated at tes } \\
\text { levels. using max } \\
\text { orbital velocity }\end{array}$ & $\begin{array}{l}\quad 3 \times 10^{4}-9 \times 10^{5} \\
\text { st section } \\
\text { ximum Airy } \\
\text { y. }\end{array}$ & $\begin{array}{l}0.1-5.0 \\
\text { Extremes of } \\
\text { Average } \\
\text { about } \\
0.5-0.7^{\text {at }} \\
\mathrm{R}_{\mathrm{e}}=5 \times 10^{5} \\
\text { increasing } \\
\text { to } 1.0 \text { and } \\
\text { above at } \\
\text { smaller } \mathrm{R}_{\mathrm{e}}\end{array}$ & $\begin{array}{l}0.7-6.0 \\
\text { scatter. } \\
2.5 \\
\text { given as } \\
\text { mean value } \\
\text { of a } \\
\text { Gaussian } \\
\text { distribu- } \\
\text { t1on. }\end{array}$ & 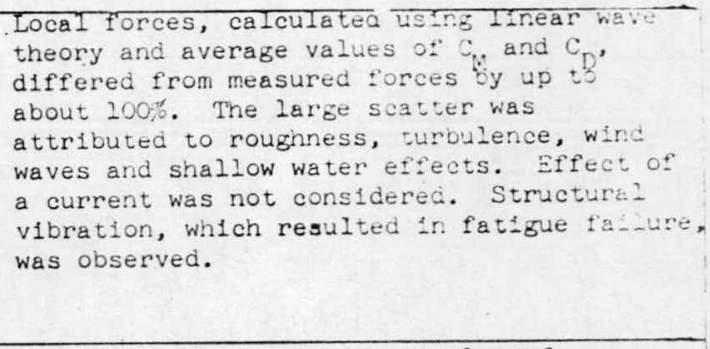 \\
\hline $\begin{array}{l}3 \pm 1 \text { son } \\
2905 \\
\text { Bet. } 2.20\end{array}$ & Gulf of Mexico & 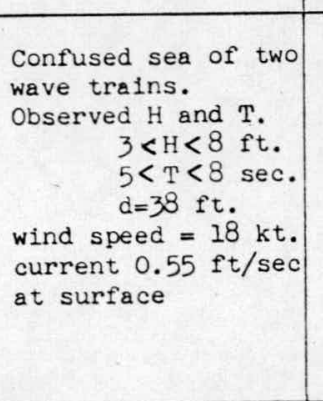 & $\begin{array}{l}\text { Vertical cylinder } \\
\text { suspended in the } \\
\text { water } \\
\qquad D=2.5 \mathrm{ft} \text {. }\end{array}$ & $5-15$ & $3 \times 1 c^{5}-10^{6}$ & $\begin{array}{l}\text { (a) } 0.32 \\
\text { current not c } \\
\text { (b) } 0.60 \\
\text { Current consic } \\
\text { (c) } 2.75 \\
\text { Current cons1c } \\
\text { and phase cor } \\
\text { between force } \\
\text { wave record } 1 \\
\text { (d) } 1.79 \\
\text { Best result } \\
\text { (b) and (c) a }\end{array}$ & $\begin{array}{l}1.53 \\
\text { considered } \\
1.54 \\
\text { idered } \\
1.36 \\
\text { ldered } \\
\text { rrection } \\
\text { e and } \\
\text { included } \\
1.53 \\
\text { from } \\
\text { averaged. }\end{array}$ & $\begin{array}{l}\text { Large scatter in } C_{D} \text { and } C_{n} \text { values from } \\
\text { different wave force record analyses; } \\
\text { correlation between calculated and } \\
\text { measured force varied from poor to very } \\
\text { good for. Individual records. A linear } \\
\text { spectral method of data anaivsis was used. } \\
C_{D} \text { values were sirnificantiy affected by } \\
\text { current; } C_{M} \text { appeared to be unaffected oj } \\
\text { the current. Structural vibration, whith } \\
\text { resulted in fatigue failure, was observed. }\end{array}$ \\
\hline
\end{tabular}


K $\Lambda$

3

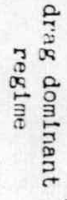

$C_{M}$ and $C_{D}$ from Keulegan and Carpenters' curves as in figure 2.3 .

$\sqrt{2}+x^{2}$

Local and total wave forces should be calculated to within except near $\mathrm{N}=15$, where the error may be large.

Box 1

$2.11,2.13,2.14,2.16,2.19$

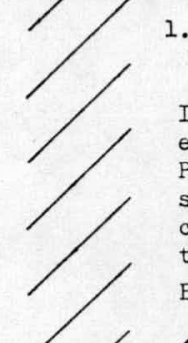
1.2

$$
C_{M}=1.5
$$
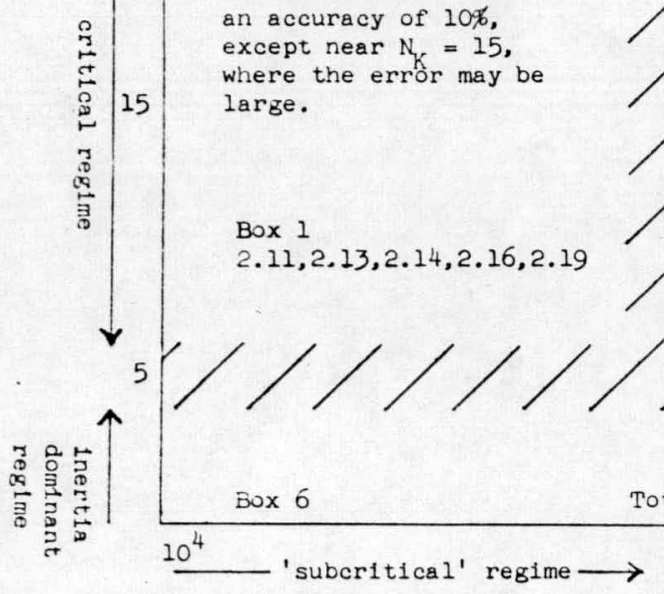

It should be noted that:(i) The $C_{M}$ and $C_{D}$ values suggested apply to isolated, smooth cylinders in deep water $\left(\left(\mathrm{d} / \mathrm{gT}^{2}\right)>0.003\right)$. No allowance has been made for
roughness, orfentation, slamming, Interaction with other members and other effects discussed $1 \mathrm{n}$ the text in sect1on 2.6 . No allowance has been made for the interactive effects of currents and waves. (see section 2.6.7)

(i1:) The $C_{M}$ and $C_{D}$ values suggested and their rellability estimates are subjective, but are based on 11 terature references given in the bottom right hand corner of each 'box', and on the discussion in the text in section 2.5 as shown by the number $1 \mathrm{n}$ the bottom left hand corner of each 'box'.

(iv) The $C_{M}$ and $C_{D}$ values suggested have been determined solely on the basis of references c1ted.

(v) The values of $\mathrm{R}$ and $\mathrm{N}_{\mathrm{K}}$ specifying the various 'boxes' are not well defined experimentally. They are simply chosen for (vi) The $C_{M}$ and $C$ values suggested should be used w1th a wave theory appropriate to the environmental conditions considered. (See
sect1on 2.7). It 1s suggested that the chosen wave theory be used to evaluate $R_{\text {and }} N_{K}$. Approximate values of the parameters $\mathrm{R}_{\mathrm{e}}$ and $\mathrm{N}_{\mathrm{K}}$ are adequate for using this figure. nertia force is small, thus any error in $M$ will not be signif Published Malues exhlbit wide calculated wave forces greater than $100 \%$ are possible.

Box 2 2.1,2.2,2.5,2.17,2.20,2.25 not be sleniflcant. Total wave forces should be in locol wave forces greater than $50 \mathrm{~d}$ are

$2.1,2.5,2.8,2.12,2.17,2.24$

$$
\mathrm{C}_{\mathrm{M}}=1.5 \quad \mathrm{C}_{\mathrm{D}}=0.6
$$

Data avallable is sparse and errors in calculated wave forces are not really known but could be greater than the case for large (H/D) at these $R_{e}$; greater than $20 \%$ and error in calculated local Box 5

$2.1,2.5,2.25,2.26$

\section{(diameter/wave length) $\approx 0.2 \quad \mathrm{C}_{M}=2.0$ drag neglig1ble $\left(\mathrm{C}_{\mathrm{D}} \equiv 0\right)$}

and local wave forces should be calculated to within an accuracy of $20 \%$

$2.3,2.6,2.9,2 \cdot 10,2 \cdot 22$ than $100 \%$ are possible.

$2.1,2.2,2.5,2.18,2.20,2.25,2.26$
Inertla force 1 s small, thus any error in $C_{M} w 11$ 


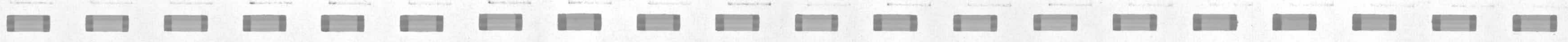

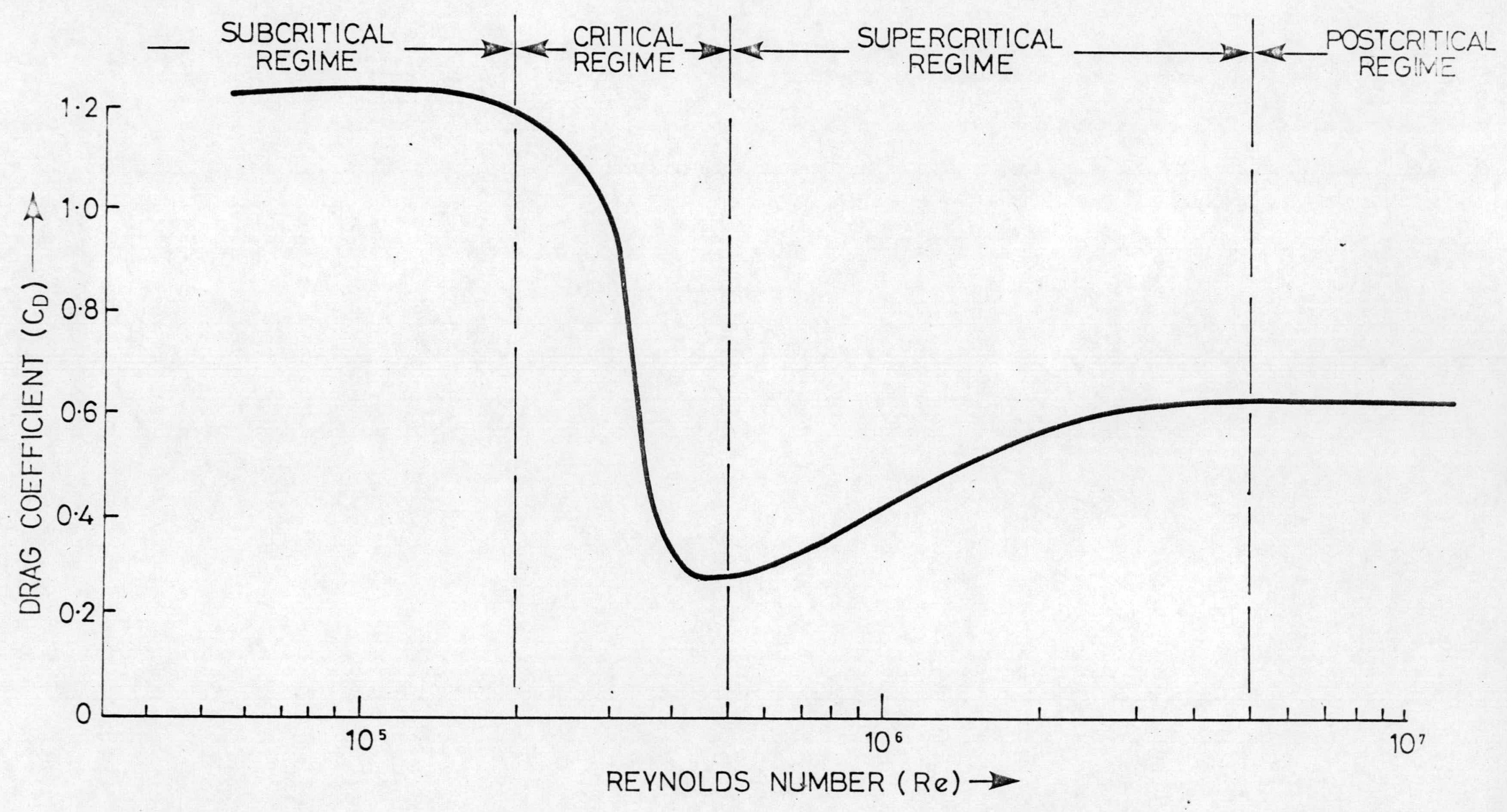

Fig. (2.2) The variation of drag coefficient with Reynolds number for a smooth cylinder in steady uniform flow 
figure $2 \cdot 3$

Suggested values of $C_{M}$ and $C_{D}$ at subcritical $R_{e}$ from Keulegan and Carpenter (Ref.2.11), for the wave force normal to the axis of a smooth cylindzr. ( 322 also figure 2.1)
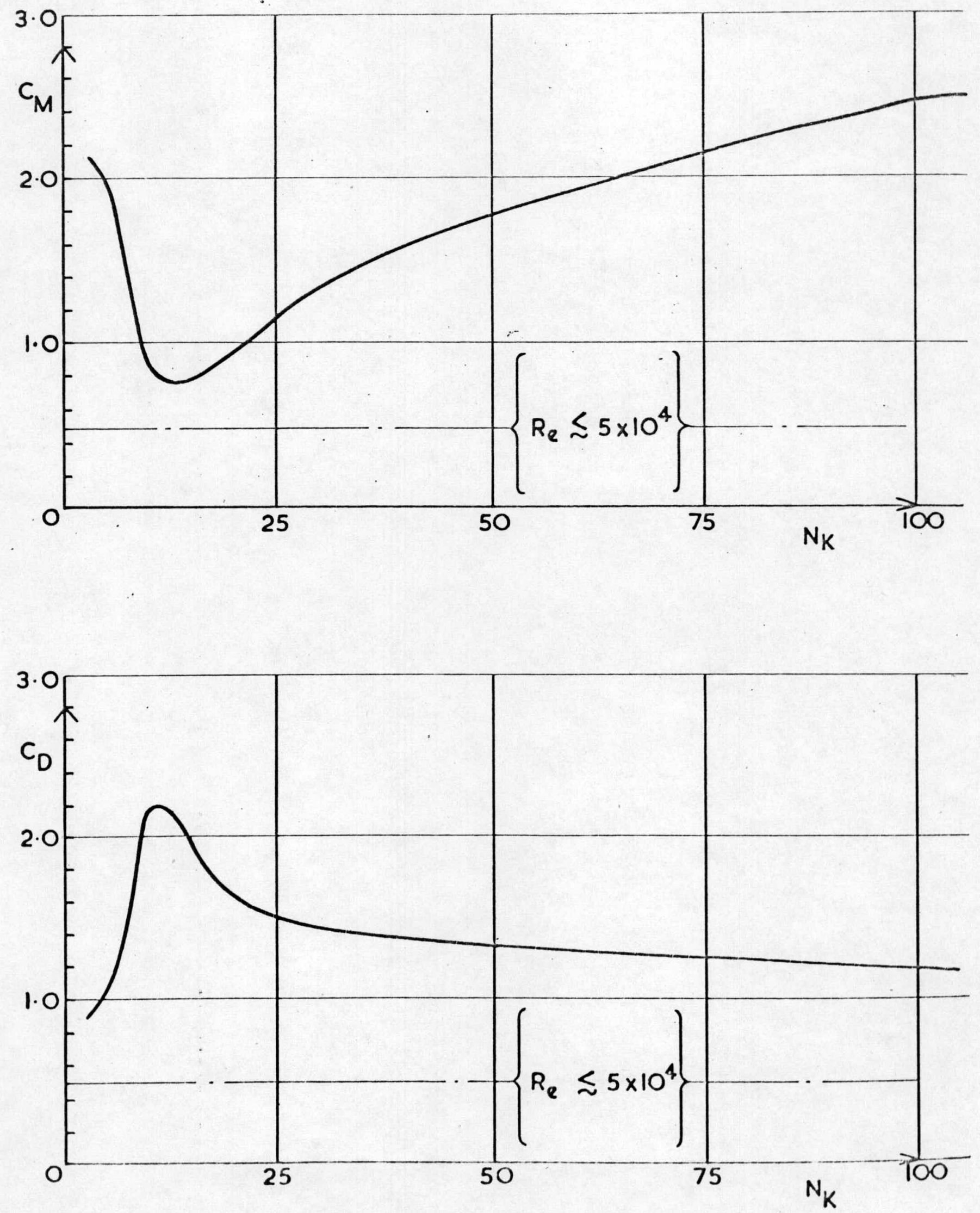
figure 2.4. Comparison between Airy linear wave theory and Stokes $5^{\text {th }}$ order wave theory of horizontal component of orbital velocity $u$, under a wave crest, and horizontal component of orbital acceleration $\dot{u}, \pi / 2$ in advance of the crest, showing the variation with depth below the wave surface.
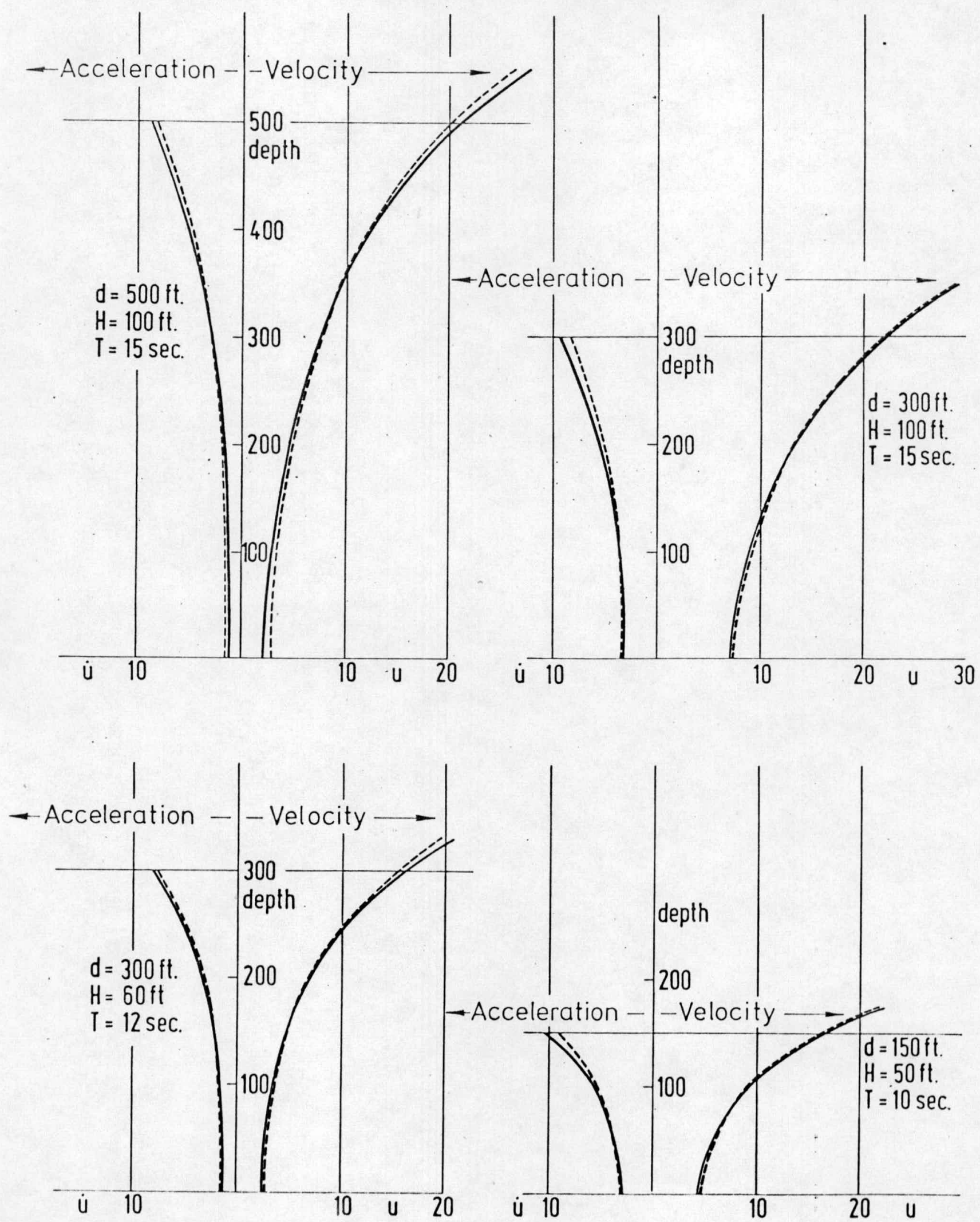
SONE PUBLISHED DOCUMENTATION OF DIFFRACTION ANALYSIS

AND ITS APPLICATIONS

FINITE EILENENT MODELLING PROGRAMS

\begin{tabular}{|c|c|c|c|c|c|}
\hline \multirow[b]{2}{*}{ AUTHORS } & \multirow[b]{2}{*}{$\begin{array}{l}\text { REEERENCE } \\
\text { NUMBERS }\end{array}$} & \multicolumn{3}{|c|}{ CAPABI LITY } & \multirow{2}{*}{$\begin{array}{c}\text { APPLICATIONS } \\
\text { FOR WHICH } \\
\text { NUMERICAL } \\
\text { RESULTS ARE } \\
\text { PRESENTED }\end{array}$} \\
\hline & & CLASS OF BODY & $\begin{array}{c}\text { FIXE:D } \\
\text { OR } \\
\text { MOVING } \\
\text { F OR M }\end{array}$ & $\begin{array}{l}\text { DRIFT } \\
\text { FORCES }\end{array}$ & \\
\hline $\begin{array}{l}\text { Bai, K.J. and } \\
\text { Yeung, R.W. }\end{array}$ & 3.14 & General & $\mathrm{F}$ and $\mathrm{M}$ & & $\begin{array}{l}\text { Rectangular } \\
\text { cylinder, circu- } \\
\text { lar dock, } \\
\text { spheres and } \\
\text { ellipsoids }\end{array}$ \\
\hline $\begin{array}{l}\text { Chen, H.S. and } \\
\text { Mei, C.C. }\end{array}$ & 3.15 & $\begin{array}{l}\text { Any wallsided } \\
\text { shape }\end{array}$ & $F$ & & $\begin{array}{l}\text { Man made } \\
\text { harbour in } \\
\text { open sea }\end{array}$ \\
\hline $\begin{array}{l}\text { Faltinsen, O. and } \\
\text { Michelsen, F.C. }\end{array}$ & 3.13 & General & $\mathrm{F}$ and $\mathrm{M}$ & Yes & $\begin{array}{l}\text { Box shaped } \\
\text { surface vessels }\end{array}$ \\
\hline Tarrison, C.J. & 3.16 & General & $\mathrm{F}$ and $\mathrm{M}$ & Yes & $\begin{array}{l}\text { Floating spheres } \\
\text { and discs, scuare } \\
\text { section caisson } \\
\text { and legs }\end{array}$ \\
\hline $\begin{array}{l}\text { Hogben, N. and } \\
\text { Standing, R.G. }\end{array}$ & $\begin{array}{l}1.7 \text { and } \\
1.8\end{array}$ & General & $\mathrm{F}$ and $\mathrm{M}$ & & $\begin{array}{l}\text { Vertical columns, } \\
\text { gravity type } \\
\text { and moored } \\
\text { platforms }\end{array}$ \\
\hline $\begin{array}{l}\text { Lebreton, J.C. and } \\
\text { cornault, P. }\end{array}$ & 3.12 & General & $\mathrm{F}$ and $\mathrm{M}$ & & $\begin{array}{l}\text { Horizontal } \\
\text { axisymmetric } \\
\text { body, vertical } \\
\text { columns }\end{array}$ \\
\hline Maeda, H. & 3.17 & $\begin{array}{l}\text { Any } 2 \text {-dimensional } \\
\text { section* }\end{array}$ & $F$ & & $\begin{array}{l}\text { Bulbous form } \\
\text { catamarans, } \\
\text { submerged circu- } \\
\text { lar cylinders }\end{array}$ \\
\hline Ian Oortmerssen, G. & .3 .18 & General & $\mathrm{F}$ & Yes & $\begin{array}{l}\text { Vertical } \\
\text { rectangular } \\
\text { column on } \\
\text { pyramidal base }\end{array}$ \\
\hline
\end{tabular}

By 'F'rank Close Fit' method - reference 3.7. 


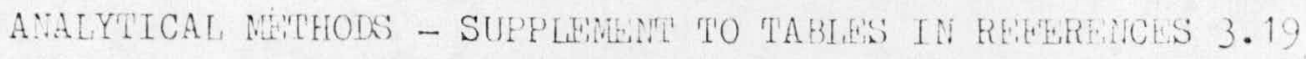

A very extensive catalogue of papers on theoretical diffraction analysis with special reference to floating platforms is given by St Denis in reference 3.19. The table below is a supplement listing some papers which are not included in the reference but have particular practical relevance to offshore structures.

\begin{tabular}{|c|c|c|c|c|c|}
\hline \multirow[b]{2}{*}{ AUTHORS } & \multirow[b]{2}{*}{$\begin{array}{l}\text { REFERENCE } \\
\text { NUNBERS }\end{array}$} & \multicolumn{3}{|c|}{ CAPABILITY } & \multirow{2}{*}{$\begin{array}{l}\text { APPLICATIOIS } \\
\text { FOR WHICH } \\
\text { NUNERICAL } \\
\text { RESULTS ARE } \\
\text { PRESENTED }\end{array}$} \\
\hline & & CLASS OF BODY & $\begin{array}{l}\text { FIXED } \\
\text { OR } \\
\text { MOVING } \\
\text { F OR M }\end{array}$ & $\begin{array}{l}\text { DRIFT } \\
\text { FORCES }\end{array}$ & \\
\hline Black, J.L. & 3.20 & $\begin{array}{l}\text { Vertical } \\
\text { axisymmetric } \\
\text { bodies }\end{array}$ & $\mathrm{F}$ & & $\begin{array}{l}\text { Sphere and } \\
\text { vertical } \\
\text { truncated } \\
\text { circular } \\
\text { cylinders }\end{array}$ \\
\hline $\begin{array}{l}\text { Black, J.L., } \\
\text { Mei, C.C. and } \\
\text { Bray, M.C.G. }\end{array}$ & 3.21 & $\begin{array}{l}\text { Vertical } \\
\text { axisymmetric } \\
\text { bodies }\end{array}$ & $F$ and $M$ & & $\begin{array}{l}\text { Horizontal } \\
\text { rectangular and } \\
\text { vertical } \\
\text { truncated circu- } \\
\text { lar cylinders }\end{array}$ \\
\hline $\begin{array}{l}\text { Chakrabarti, S.K. } \\
\text { and Tam, W.A. }\end{array}$ & 3.1 & $\begin{array}{l}\text { Vertical circular } \\
\text { cylinder }\end{array}$ & $F$ & & $\begin{array}{l}\text { Vertical } \\
\text { circular } \\
\text { cylinder }\end{array}$ \\
\hline Garrett, C.J.R: & 3.22 & $\begin{array}{l}\text { Vertical circular } \\
\text { cylinders }\end{array}$ & $\mathrm{F}$ & & $\begin{array}{l}\text { Truncated } \\
\text { floating } \\
\text { vertical circu- } \\
\text { lar cylinder }\end{array}$ \\
\hline Gran, S. & 3.23 & $\begin{array}{l}\text { Vertical } \\
\text { axisymmetric body } \\
\text { in long waves }\end{array}$ & $F$ & & $\begin{array}{l}\text { Truncated } \\
\text { vertical circu- } \\
\text { lar cylinder }\end{array}$ \\
\hline Havelock, T.H. & 3.8 & $\begin{array}{l}\text { Vertical circular } \\
\text { cylinder in deep } \\
\text { water }\end{array}$ & $F$ & Yes & $\begin{array}{l}\text { Vertical circu- } \\
\text { lar cylinder in } \\
\text { deep water }\end{array}$ \\
\hline $\begin{array}{l}\text { Kokkinowrachos, K. } \\
\text { and Wilckens, H. }\end{array}$ & 3.24 & $\begin{array}{l}\text { Vertical } \\
\text { axisymmetric } \\
\text { bodies }\end{array}$ & $\mathrm{F}$ and $\mathrm{M}$ & & $\begin{array}{l}\text { Composite'verti- } \\
\text { cal circular } \\
\text { cylinders }\end{array}$ \\
\hline $\begin{array}{l}\text { MacCamy, R.C. } \\
\text { and Fuchs, R.A. }\end{array}$ & 3.9 & $\begin{array}{l}\text { Vertical circular } \\
\text { cylinder in } \\
\text { shallow water }\end{array}$ & $\mathrm{F}$ & & $\begin{array}{l}\text { Vertical circu- } \\
\text { lar cylinder in } \\
\text { shallow water }\end{array}$ \\
\hline $\begin{array}{l}\text { Mil gram, J.H. and } \\
\text { Halkyard, J.E. }\end{array}$ & 3.25 & $\begin{array}{l}\text { Vertical } \\
\text { axisymmetric } \\
\text { bodies }\end{array}$ & $\mathrm{F}$ & & $\begin{array}{l}\text { Spheres and } \\
\text { circular } \\
\text { cylinder atop } \\
\text { sphere }\end{array}$ \\
\hline Ohkusu, M. & 3.26 & $\begin{array}{l}\text { Multiple vertical } \\
\text { or horizontal } \\
\text { cylinders }\end{array}$ & $F$ and $M$ & & $\begin{array}{l}\text { Multiple verti- } \\
\text { cal and } \\
\text { horizontal } \\
\text { circular } \\
\text { cylinders }\end{array}$ \\
\hline
\end{tabular}




\begin{tabular}{|c|c|c|}
\hline AUTHORS & $\begin{array}{l}\text { REFERENCE } \\
\text { NUMTERS }\end{array}$ & CLASS OF BODY AND REVARKS \\
\hline Bo $\cdots, 1, L$ & 3.27 & $\begin{array}{l}\text { Square section column on pyramidal base. Includes } \\
\text { detailed comparisons with measured pressure distribu- } \\
\text { tions }\end{array}$ \\
\hline Breren et al & 3.11 & $\begin{array}{l}\text { Bell shaped storage tank. Comparison with preliminary } \\
\text { full scale pressure measurements }\end{array}$ \\
\hline Shakrabarti, S.K. & 3.10 & 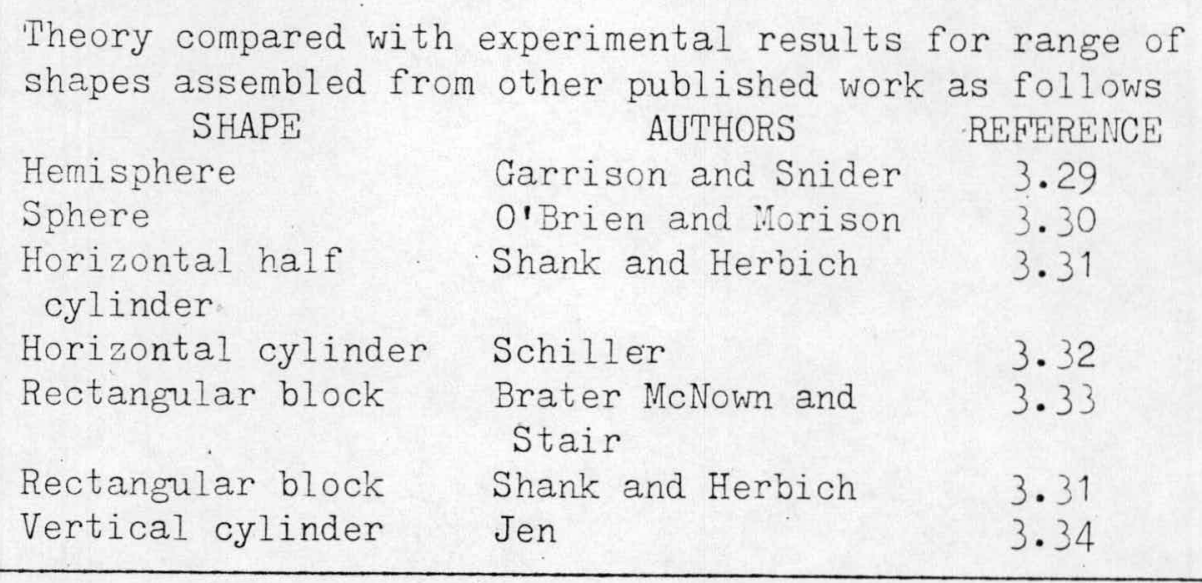 \\
\hline $\begin{array}{l}\text { 'hakrabarti, S.K. } \\
\text { and Tarn, W.A. }\end{array}$ & 3.1 & $\begin{array}{l}\text { Surface piercing vertical cylinder. Includes compari- } \\
\text { son with measured pressure distributions }\end{array}$ \\
\hline $\begin{array}{l}\text { Taltinsen, } 0 \text {. and } \\
\text { Wichelsen, F.C. }\end{array}$ & 3.13 & $\begin{array}{l}\text { Box shaped floating vessels. Comparisons with } \\
\text { measured forces (including drift forces) and motions }\end{array}$ \\
\hline Tarrison, C.J. & 3.16 & Heave and pitch motions of a disc buoy \\
\hline Garrison et al & 3.28 & Model of gravity platform (Condeep) \\
\hline ran, $\mathrm{S}$ & 3.23 & $\begin{array}{l}\text { Theory for truncated vertical cylinder compared with } \\
\text { model results for gravity platform base (Condeep) }\end{array}$ \\
\hline $\begin{array}{l}\text { ogben, N. and } \\
\text { standing, R.G. }\end{array}$ & $\begin{array}{l}1.7 \text { and } \\
1.8\end{array}$ & Circular and square section columns of varying height \\
\hline $\begin{array}{l}\text { ebreton, J.C. and } \\
\text { ormault, P. }\end{array}$ & 3.12 & Vertical circular cylinders of varying height \\
\hline Man Oortmerssen & 3.18 & $\begin{array}{l}\text { Square section column on pyramidal base. Some } \\
\text { pressure measurements included. }\end{array}$ \\
\hline
\end{tabular}



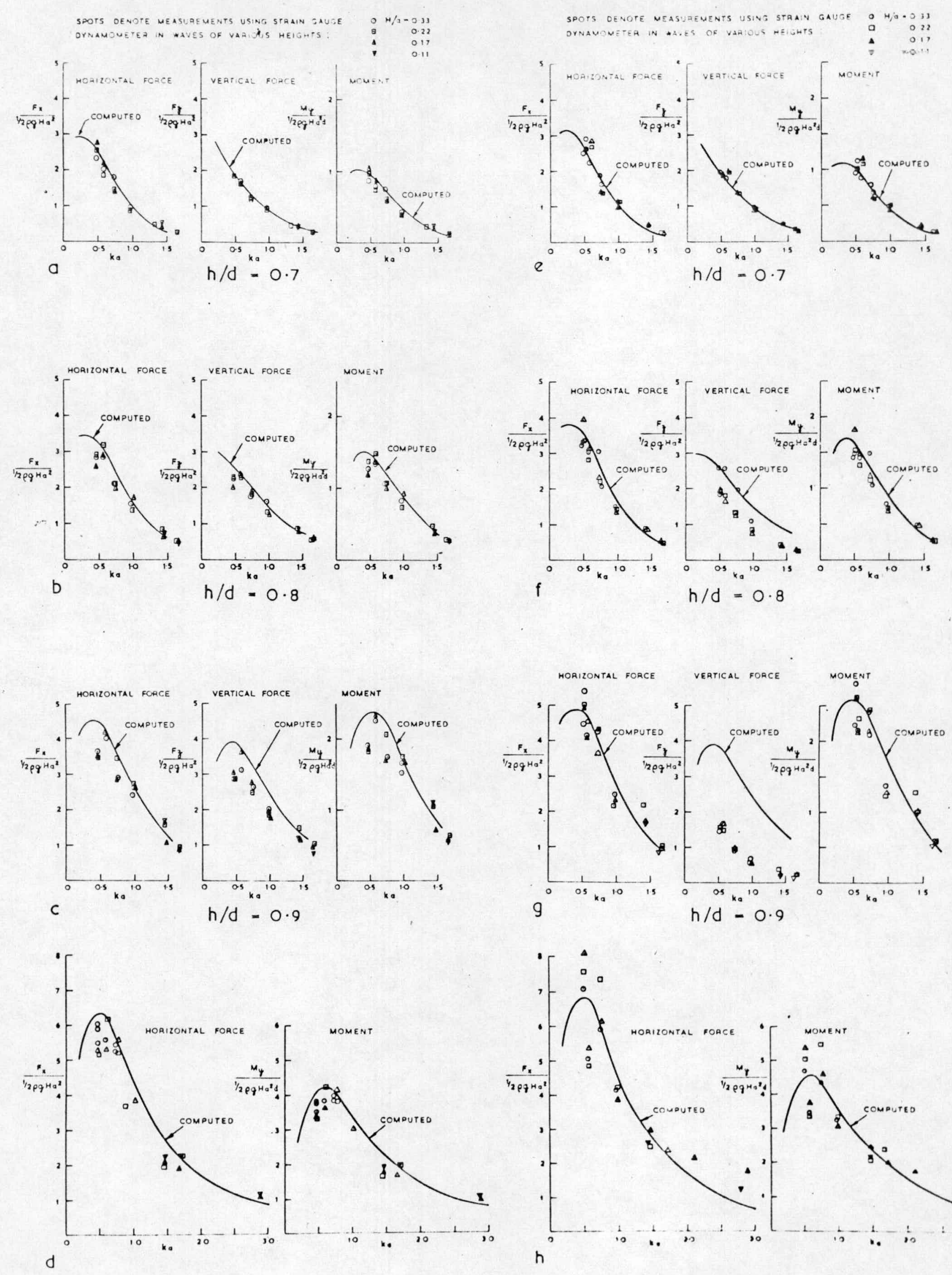

SURFACE PIERCING

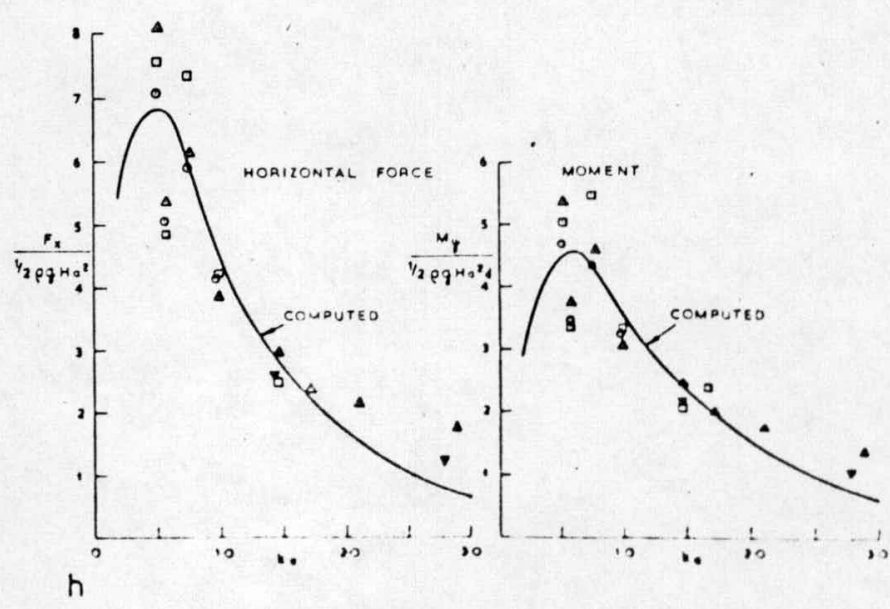

SURFACE PIERCINIG

Figure 3.1 Comparizon of Computed and Mosured Forces and Moments on a Series of Circular and Squire Section Columns with Various Ratios of Helght'h ' to 'Hater Depth 'd' (Eron Heference 1.7). 


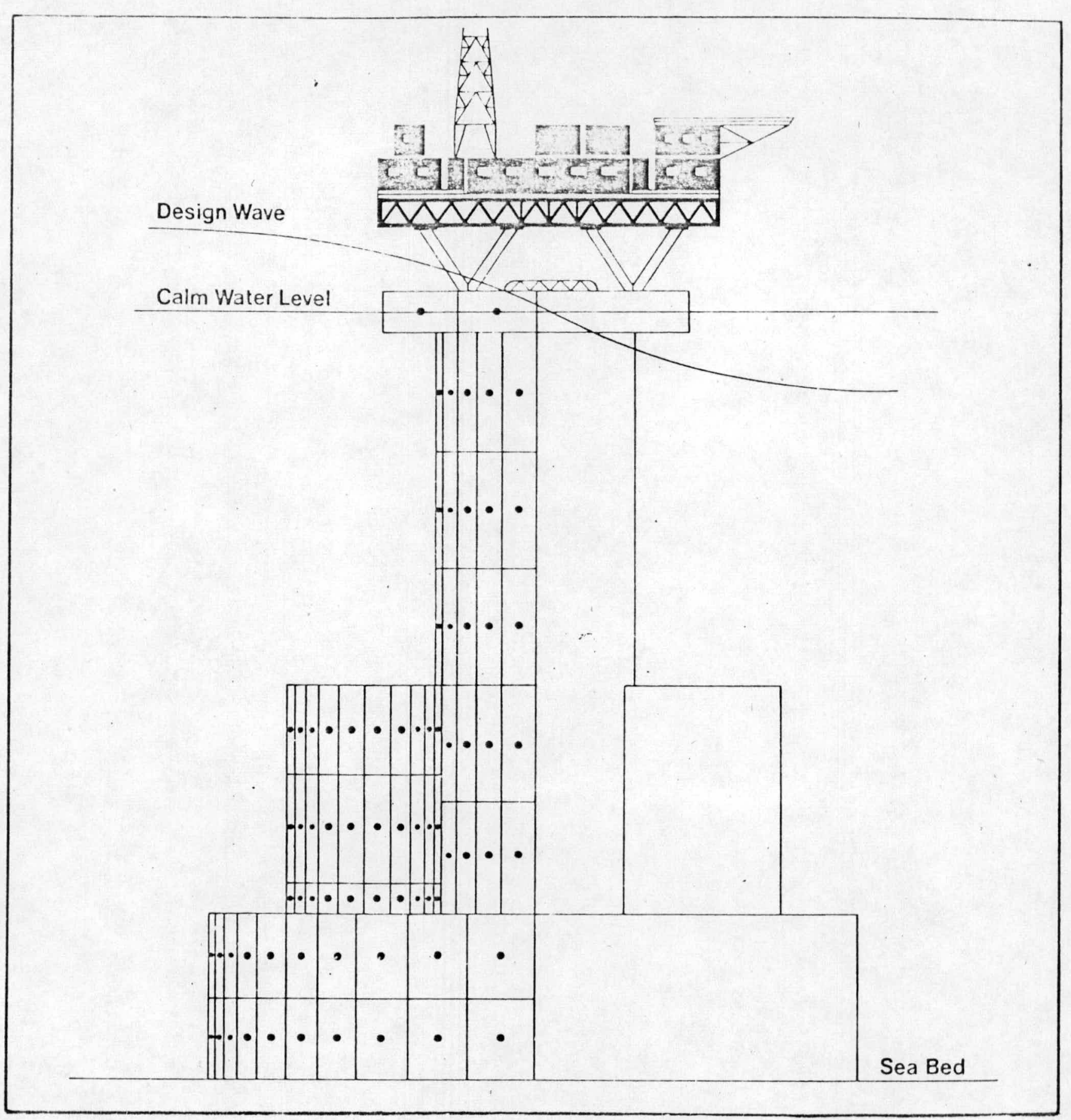

Figure 3.2 Sample Modelling of a Gravity Structure (From SIA leaflet for 'NPLWAVE' Programme). 


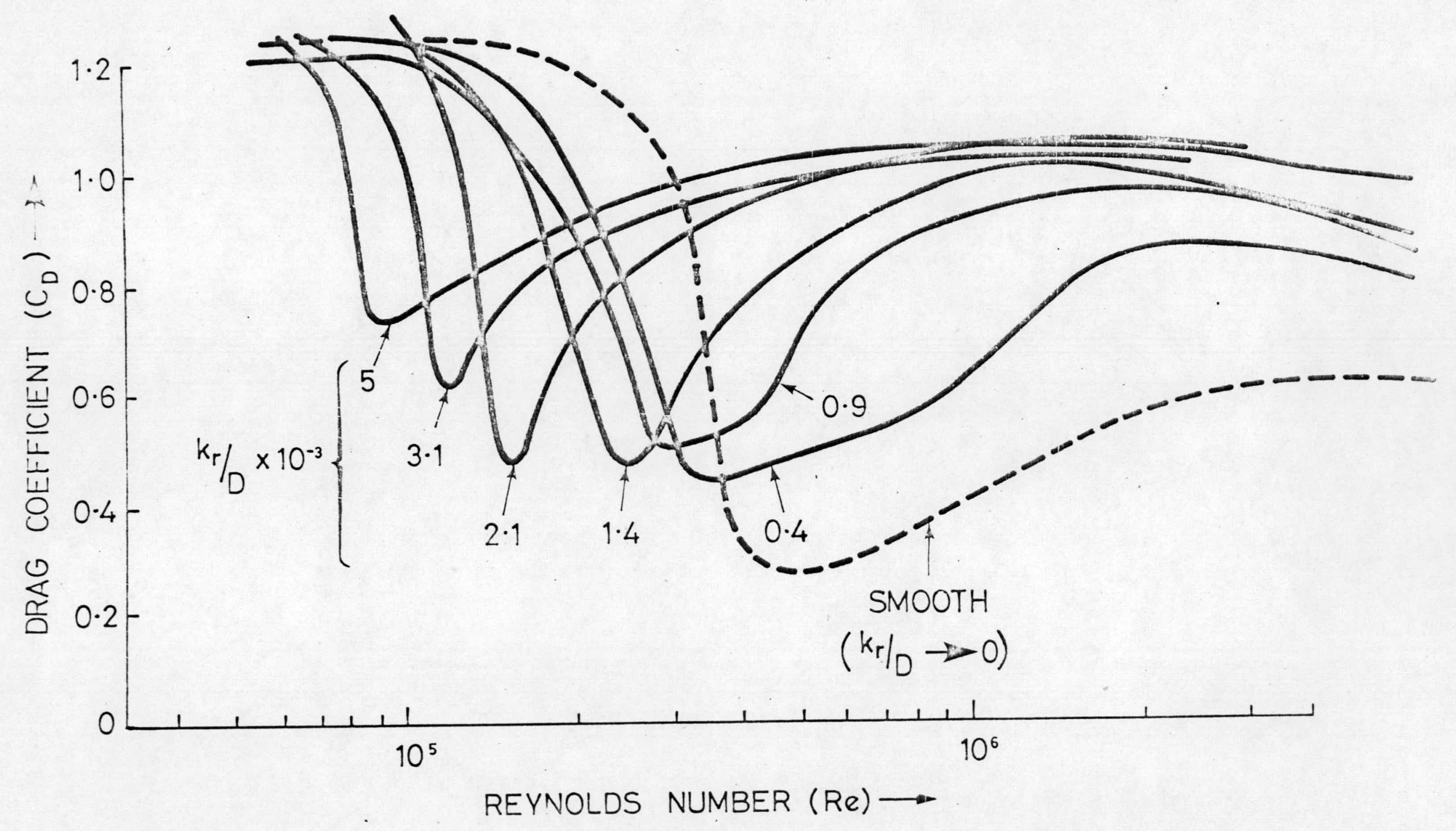

Fig.(4.1) The drag of sand-roughened cylinders 


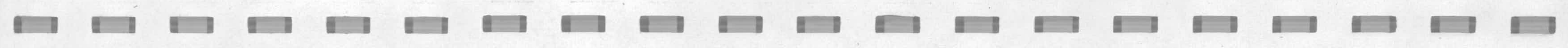

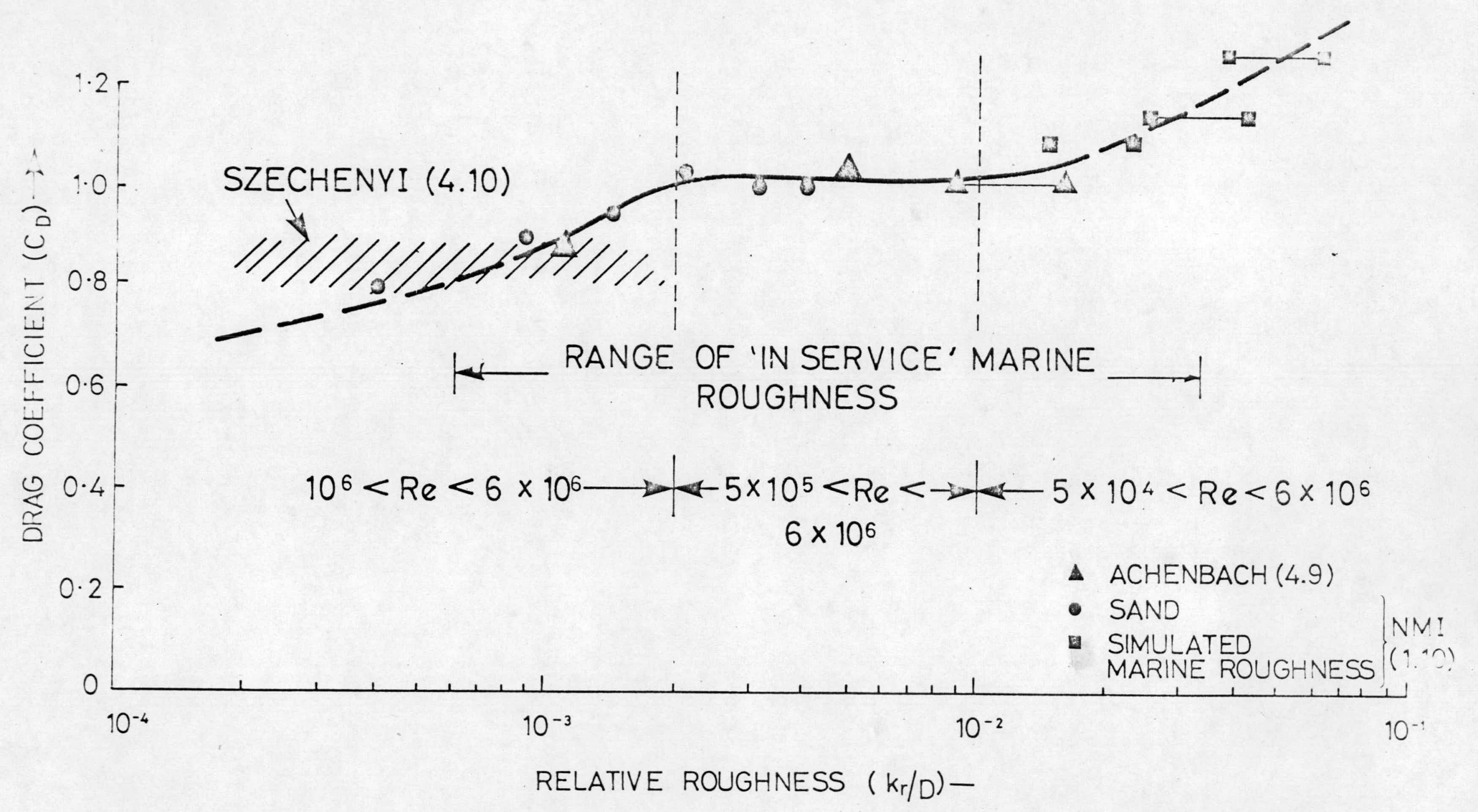

Fig. (4.2) Drag of rough cylinders at high Reynolds numbers 


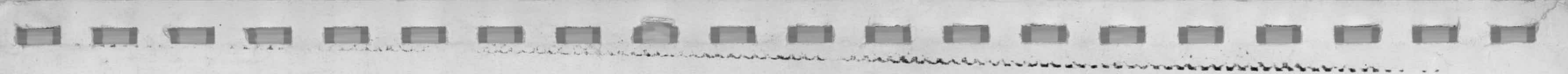

ESTIIATION OF FLUID LOADING ON OFFSHORE

NVIT in STRUCTURES 